\title{
CATALYTIC COMBUSTION OF SYNGAS
}

\author{
John Mantzaras \\ Paul Scherrer Institute, Combustion Research, Villigen PSI, Switzerland
}

The catalytic combustion of syngaslair mixtures over Pt has been investigated numerically in a channel-flow configuration using $2 D$ steady and transient computer codes with detailed hetero-Ihomogeneous chemistry, transport, and heat transfer mechanisms in the solid. Simulations were carried out for syngas compositions with varying $\mathrm{H}_{2}$ and $\mathrm{CO}$ contents, pressures of 1 to $15 \mathrm{bar}$, and linear velocities relevant to power generation systems. It is shown that the homogeneous (gas-phase) chemistry of both $\mathrm{H}_{2}$ and $\mathrm{CO}$ cannot be neglected at elevated pressures, even at the very large geometrical confinements relevant to practical catalytic reactors. The diffusional imbalance of hydrogen can lead, depending on its content in the syngas, to superadiabatic surface temperatures that may endanger the catalyst and reactor integrity. On the other hand, the presence of gas-phase $\mathrm{H}_{2}$ combustion moderates the superadiabatic wall temperatures by shielding the catalyst from the hydrogen-rich channel core. Above a transition temperature of about $700 \mathrm{~K}$, which is roughly independent of pressure and syngas composition, the heterogeneous (catalytic) pathways of $\mathrm{CO}$ and $\mathrm{H}_{2}$ are decoupled, while the chemical interactions between the heterogeneous pathway of each individual fuel component with the homogeneous pathway of the other are minimal. Below the aforementioned transition temperature the catalyst is covered predominantly by $\mathrm{CO}$, which in turn inhibits the catalytic conversion of both fuel components. While the addition of carbon monoxide in hydrogen hinders the catalytic ignition of the latter, there is no clear improvement in the ignition characteristics of $\mathrm{CO}$ by adding $\mathrm{H}_{2}$. Strategies for reactor thermal management are finally outlined in light of the attained superadiabatic surface temperatures of hydrogen-rich syngas fuels.

Keywords: Catalytic ignition; Hetero-/homogeneous syngas combustion; Platinum catalyst; Syngas catalytic combustion

\section{INTRODUCTION}

Synthesis gas (syngas), apart from its widespread use for the synthesis of various chemicals (Wender, 1996), has recently attracted increased attention as an environmentally clean fuel that can facilitate nearly zero emission combustion strategies in gas turbines of power generation systems (Neathery et al., 1999; Karim et al., 2002; Griffin et al., 2005). Additional studies in automotive internal combustion engines have also explored the use of syngas fuels for reduced emissions and enhanced combustion stability (Allgeier et al., 2004; Boehman and Le Corre, 2008).

Support was provided by the Swiss Federal Office of Energy (BFE), the Swiss Commission of Technology and Innovation (KTI) under contract No. 8457.2, and ALSTOM Power of Switzerland.

Address correspondence to John Mantzaras, Paul Scherrer Institute, Combustion Research, CH-5232 Villigen PSI, Switzerland. E-mail: ioannis.mantzaras@psi.ch 
The further reduction of $\mathrm{NO}_{\mathrm{x}}$ and greenhouse $\mathrm{CO}_{2}$ emissions in power generation systems necessitates the use of methods other than -or in addition tothe conventional tail-end capture approaches. Front-end measures such as fuel decarbonization lead to syngas or hydrogen-rich containing fuels, whose homogeneous (gas-phase) combustion characteristics have been investigated systematically only very recently (Chaos and Dryer, 2008; Walton et al., 2007). Hydrogen-rich fuels can either be produced in a separate unit (gasifier followed by a water-gas-shift reactor) or, in the case of natural-gas-fired turbines, in situ in short contact time catalytic partial oxidation (CPO) reactors (Griffin et al., 2004; Eriksson et al., 2006; Schneider et al., 2006). Integrated measures that include oxy-fuel combustion (combustion in pure oxygen separated from air) mitigate $\mathrm{NO}_{\mathrm{x}}$ emissions and also facilitate the capture of $\mathrm{CO}_{2}$ (e.g., via water condensation) due to the absence of $\mathrm{N}_{2}$ in the flue gases. In some of the oxy-fuel approaches, as for example in the advanced zero emissions combustion concept (Griffin et al., 2004), combustion is accomplished at low oxygen excess in the presence of large exhaust gas recycle (EGR, up to $80 \%$ vol. $\mathrm{H}_{2} \mathrm{O}$ and $\mathrm{CO}_{2}$ in the feed) so as to operate efficiently the air separation unit and to increase the content of $\mathrm{CO}_{2}$ in the flue gases. In such approaches, the use of catalytic combustion appears particularly promising as discussed next.

Catalytic combustion in power generation systems has initially been pursued within the context of catalytically stabilized thermal combustion (CST), which is the most cost-effective ultra-low- $\mathrm{NO}_{\mathrm{x}}$ combustion technology for natural-gas-fired turbines (Schlegel et al., 1996; ONSE, 1999; Beebe et al., 2000). In CST roughly half of the fuel is converted heterogeneously (catalytically) in Pd- and/or Pt-coated honeycomb reactors and the remaining is combusted in a follow-up homogeneous burnout zone (Beebe et al., 2000; Carroni et al., 2002). A more recent approach, referred to as "catalytic rich gaseous lean" combustion, entails CPO of natural gas with part of the air stream (Karim et al., 2002; Schneider et al., 2006).

Part of the fuel is converted inside the CPO reactor, while the products (mainly synthesis gas and unconverted methane) are subsequently mixed with the remaining air and stabilize a post-catalyst fuel-lean homogeneous combustion zone. The last methodology has a number of advantages compared to the conventional CST, the two most prominent ones being the lower catalyst light-off temperature and the enhanced stability of the follow-up flame due to the CPO-produced hydrogen (Griffin et al., 2004). The catalytic rich combustion methodology is also applicable to syngas fuels. In this case the catalyst does not have a prime CPO function (at least for syngas fuels with low methane content) but acts as a preheater and stabilizer for the follow-up homogeneous combustion zone. This approach is suitable for a wide range of syngas-based fuels that include low calorific value fuels, whereby flame stability is an issue, and also for hydrogen-rich coalderived syngas where lean-premixed combustion entails the risk of flame flash back. Those advantages, along with the control of the catalytic conversion by the air and not by the fuel supply, have led to the development of integrated hetero-/ homogeneous, combustors for coal-derived syngas and high-hydrogen containing fuels (Etemad et al., 2004).

CST can be a viable combustion technology not only for natural gas but also for syngas or syngas-rich fuels. In particular, catalytic combustion approaches appear well-suited for the low calorific value syngas-based fuels due to the associated 
lower combustion temperatures. Depending on the employed power generation cycle, the fuel can either be syngas with varying $\mathrm{H}_{2} / \mathrm{CO}$ composition, or a mixture of syngas and natural gas diluted with total oxidation products (Griffin et al., 2004; Appel et al., 2005a; Eriksson et al., 2006). Catalytic combustion is an option for all the aforementioned fuels and especially for those cycles involving large EGR due to the resulting low gas-phase reactivity and moderate combustion temperatures of the diluted reaction mixtures. For the catalytic segment of CST (the ensuing gas-phase combustion is outside the scope of this article), there have only been limited investigations. In particular, Groppi et al. (1996) studied the catalytic combustion of syngas/air over magnesium-substituted hexaaluminates in monolithic honeycomb reactors; for biogas fuels, Pt- and Pd-based catalysts have been tested in Zwinkels et al. (1993) and Pocoroba et al. (2000), while metal oxide catalysts (hexaaluminates and peruvskites) have been studied in Johansson et al. (2002).

Although typical honeycomb catalytic reactors have sufficiently large surfaceto-volume ratios so as to promote heterogeneous fuel conversion, the impact of gaseous chemistry cannot be always ignored at elevated pressures (Reinke et al., 2004; Mantzaras, 2006a). The assessment of the heterogeneous and low-temperature gaseous kinetics at turbine-relevant conditions is a demanding task. To this direction, Mantzaras and co-workers (Dogwiler et al., 1998; Appel et al., 2002; Reinke et al., 2004) introduced the methodology of in situ spatially resolved Raman measurements of major gas-phase species concentrations and laser induced fluorescence of radicals $\left(\mathrm{OH}\right.$ or $\left.\mathrm{CH}_{2} \mathrm{O}\right)$ over the catalyst boundary layer as a direct means to assess, in conjunction with detailed numerical predictions, the catalytic and gasphase reactivities at realistic operating conditions.

Appel et al. (2002) have provided validated hetero-/homogeneous reaction schemes for fuel-lean combustion of $\mathrm{H}_{2}$ /air mixtures over $\mathrm{Pt}$ catalysts at atmospheric pressure. Subsequent studies (Reinke et al., 2002, 2004, 2005, 2007) furnished refined hetero-/homogeneous reaction schemes for the total oxidation of fuel-lean $\mathrm{CH}_{4}$ /air mixtures, with and without EGR, over Pt at pressures up to 16 bar. Appel et al. (2005a) extended the aforementioned methodology to the catalytic partial oxidation of $\mathrm{CH}_{4}$ /air mixtures to syngas over $\mathrm{Rh}$ at 6 bar, while Schneider et al. (2007) investigated the hetero-/homogeneous kinetics in CPO of methane over Rh with large EGR at pressures of 4 to 10 bar.

The present article undertakes a numerical investigation of the catalytic combustion of syngas/air mixtures with different $\mathrm{H}_{2} / \mathrm{CO}$ compositions. Literature experiments are also used for the extraction of appropriate chemical kinetic schemes at industrially-relevant operating conditions. Numerical predictions are carried out in typical catalytic reactor geometries using a full elliptic $2 \mathrm{D}$ code (steady or transient) with detailed chemistry, transport, and heat transfer mechanisms in the solid. Platinum is the chosen catalyst due to its well-studied kinetics and its good reactivity for the oxidation of both $\mathrm{H}_{2}$ and $\mathrm{CO}$. Although metal oxides have also been used as catalysts for syngas combustion (Groppi et al., 1996), their activity at the high linear velocities encountered in power generation systems is not warranted.

The main objective of this work is to study the combustion characteristics of the two syngas components $\left(\mathrm{H}_{2}\right.$ and $\left.\mathrm{CO}\right)$, to investigate the heterogeneous chemical 


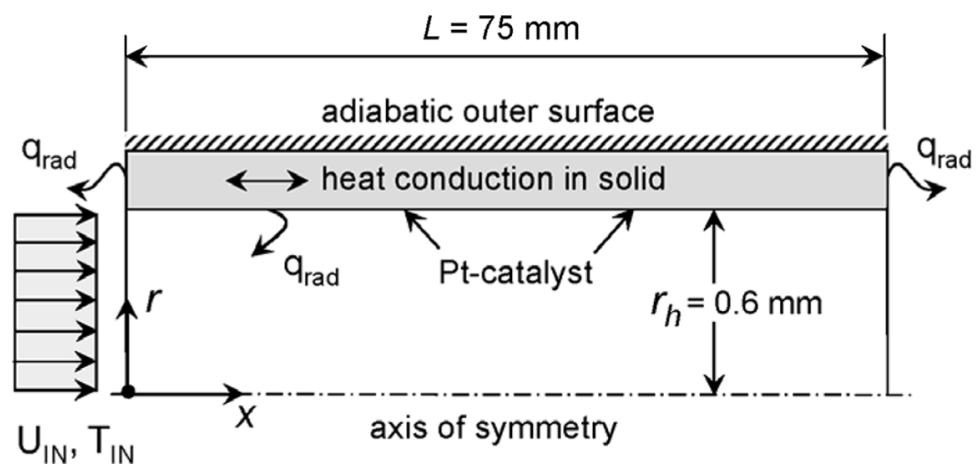

Figure 1 Catalytic channel configuration used in the simulations.

coupling of $\mathrm{CO}$ and $\mathrm{H}_{2}$, to examine the impact of gas-phase chemistry in realistic catalytic reactor geometries and pressures, and finally to address reactor thermal management issues in light of the diffusional imbalance of hydrogen that gives rise to superadiabatic surface temperatures.

\section{NUMERICAL METHODOLOGY}

Parametric studies are carried out for a single representative channel of a catalytic honeycomb reactor using a full elliptic 2D numerical code. Stationary performance is investigated with a steady model, whereas dynamic light-off behavior is addressed with a transient model. The fuel is syngas with varying $\mathrm{H}_{2} / \mathrm{CO}$ composition, while the mixture preheat and pressure range from 300 to $700 \mathrm{~K}$ and from 1 to 15 bar, respectively. For comparison purposes, pure $\mathrm{H}_{2}$ or $\mathrm{CO}$ fuels are also considered. For catalyst thermal stability reasons, the syngas composition is such that in most cases the adiabatic equilibrium temperature does not exceed 1300 K. Such high temperatures can still be tolerated by Pt-based catalysts.

The modeled geometry (see Fig. 1) considers a honeycomb channel as an equivalent cylindrical tube with length $L=75 \mathrm{~mm}$ and internal radius $r_{h}=0.6 \mathrm{~mm}$, leading to confinements (surface-to-volume ratios) typical to those encountered in commercial catalytic reactors (Groppi et al., 1996; Eriksson et al., 2006; Schneider et al., 2006). The solid substrate has a thickness $\delta=50 \mu \mathrm{m}$. Axial heat conduction in the solid is accounted for with a thermal conductivity $\lambda_{s}=16 \mathrm{~W} / \mathrm{mK}$, corresponding to FeCr-alloy metallic honeycomb structures (Appel et al., 2005a; Schneider et al., 2006).

For dynamic performance, the steady 2D model has recently been extended to transient (Schneider et al., 2008); the time scale disparity between the solid and the gas allows for the quasisteady gas-phase approximation, such that transient terms are retained only for the solid phase (Sinha et al., 1985; Schwiedernoch et al., 2003). Additional properties needed in the transient model are the specific heat capacity and density of the FeCr-alloy solid, $c_{s}=700 \mathrm{~J} / \mathrm{kgK}$ and $\rho_{s}=7220 \mathrm{~kg} / \mathrm{m}^{3}$, respectively. 


\section{Governing Equations}

The governing equations in cylindrical coordinates are:

Continuity:

$$
\frac{\partial(\rho u)}{\partial x}+\frac{1}{r} \frac{\partial(r \rho v)}{\partial r}=0
$$

Axial momentum:

$$
\begin{aligned}
\frac{\partial(\rho u u)}{\partial x}+\frac{1}{r} \frac{\partial(r \rho v u)}{\partial r}= & -\frac{\partial p}{\partial x}+\frac{\partial}{\partial x}\left[2 \mu \frac{\partial u}{\partial x}-\frac{2}{3} \mu\left(\frac{\partial u}{\partial x}+\frac{1}{r} \frac{\partial(r v)}{\partial r}\right)\right] \\
& +\frac{1}{r} \frac{\partial}{\partial r}\left[\mu r\left(\frac{\partial u}{\partial r}+\frac{\partial v}{\partial x}\right)\right] .
\end{aligned}
$$

Radial momentum:

$$
\begin{aligned}
\frac{\partial(\rho u v)}{\partial x}+\frac{1}{r} \frac{\partial(r \rho v v)}{\partial r}= & -\frac{\partial p}{\partial r}+\frac{\partial}{\partial x}\left[\mu\left(\frac{\partial v}{\partial x}+\frac{\partial u}{\partial r}\right)\right] \\
& +\frac{\partial}{\partial r}\left[2 \mu \frac{\partial v}{\partial r}-\frac{2}{3} \mu\left(\frac{\partial u}{\partial x}+\frac{1}{r} \frac{\partial(r v)}{\partial r}\right)\right] \\
& +\frac{2 \mu}{r}\left(\frac{\partial v}{\partial r}-\frac{v}{r}\right)
\end{aligned}
$$

Total enthalpy:

$$
\begin{aligned}
\frac{\partial(\rho u h)}{\partial x}+\frac{\partial(r \rho v h)}{\partial r}= & \frac{\partial}{\partial x}\left(\lambda_{g} \frac{\partial T}{\partial x}-\rho \sum_{k=1}^{K_{g}} Y_{k} h_{k} V_{k, x}\right) \\
& +\frac{1}{r} \frac{\partial}{\partial r}\left(r \lambda_{g} \frac{\partial T}{\partial r}-r \rho \sum_{k=1}^{K_{g}} Y_{k} h_{k} V_{k, r}\right)
\end{aligned}
$$

Gas-phase species:

$$
\begin{aligned}
\frac{\partial\left(\rho u Y_{k}\right)}{\partial x}+\frac{1}{r} \frac{\partial\left(r \rho v Y_{k}\right)}{\partial r}= & -\frac{\partial}{\partial x}\left(\rho Y_{k} V_{k, x}\right)-\frac{1}{r} \frac{\partial}{\partial r}\left(r \rho Y_{k} V_{k, r}\right) \\
& +\dot{\omega}_{k} W_{k}, \quad k=1, \ldots, k_{g} .
\end{aligned}
$$

Surface species coverage:

$$
\sigma_{m} \frac{\dot{s}_{m}}{\Gamma}=0, \quad m=1, \ldots, M_{s}
$$

In Eqs. (1) to (5), $u$ and $v$ are the axial and radial velocity components, while $p, \rho, \mu$, and $\lambda_{g}$ are the gas pressure, density, dynamic viscosity, and thermal conductivity, respectively; $h_{k}, Y_{k}, \vec{V}_{k}, \dot{\omega}_{k}$, and $W_{k}$ are the total enthalpy, mass fraction, diffusion velocity, homogeneous molar reaction rate, and molecular weight of the $k$-th gaseous species, respectively. In Eqs. (6), $\sigma_{m}$ and $\dot{s}_{m}$ are the site-occupancy and molar catalytic reaction rate of the $m$-th surface species, respectively, while $\Gamma$ is the surface site density. 
The diffusion velocities are calculated using mixture-average plus thermal diffusion for the light species (Kee et al., 1996a):

$$
\vec{V}_{k}=-\left(D_{k m} / Y_{k}\right) \nabla Y_{k}+\left(D_{k}^{T} / \rho Y_{k} T\right) \nabla T \quad k=1, \ldots, K_{g}
$$

with $D_{k m}$ and $D_{k}^{T}$ the mixture-average and thermal diffusion coefficient of the $k$-th gaseous species, respectively. Finally, the ideal gas and caloric state laws are:

$$
\begin{aligned}
& p=\frac{\rho R T}{\bar{W}} \quad \text { and } \quad h_{k}=h_{k}^{\mathrm{o}}\left(T_{\mathrm{o}}\right)+\int_{T_{\mathrm{o}}}^{T} c_{p, k} d T, \\
& \text { with } h=\sum_{k=1}^{K_{g}} Y_{k} h_{k}, \quad k=1, \ldots, K_{g}
\end{aligned}
$$

The energy balance for the $1 \mathrm{D}$ solid is:

$$
\begin{aligned}
& {\left[\rho_{\mathrm{s}} c_{s} \frac{\partial T_{w}}{\partial t}-\lambda_{\mathrm{s}} \frac{\partial^{2} T_{w}}{\partial x^{2}}\right] \frac{\delta}{2}} \\
& \quad-\left[\dot{q}_{\mathrm{rad}}-\left.\lambda_{g} \frac{\partial T}{\partial r}\right|_{r=r_{h^{-}}}+\sum_{k=1}^{K_{g}}\left(\dot{s}_{k} h_{k} W_{k}\right)_{r=r_{h}}\right]\left(\frac{2 r_{h}}{2 r_{h}+\delta / 2}\right)=0,
\end{aligned}
$$

with $T_{W}$ the solid wall temperature. The first term on the left side of Eq. (9) is only included in the transient simulations. The solid thickness in Eq. (9) corresponds to half of the channel wall $(\delta / 2=25 \mu \mathrm{m})$ due to the consideration of adjacent channels.

The net received radiant heat flux $\left(\dot{q}_{\text {rad }}\right)$ accounts for the radiation exchange of each differential cylindrical surface element with all other differential surface elements as well as with the channel entry and outlet, and is modeled by the net radiation method for diffuse-gray areas (Siegel and Howell, 1981). Details of the radiation model have been provided elsewhere (Karagiannidis et al., 2007). The emissivities of all differential channel elements are equal to $\varepsilon=0.6$, while the inlet and the outlet sections are treated as black bodies $(\varepsilon=1.0)$. The radiation exchange temperatures for the entry and outlet are equal to the corresponding mean gas temperatures.

\section{Boundary Conditions}

The gas-phase species interfacial boundary conditions are:

$$
\left(\rho Y_{k} V_{k, r}\right)_{r=r_{h^{-}}}+\dot{s}_{k} W_{k}=0, \quad k=1, \ldots, K_{g}
$$

Radiative boundary conditions are applied for the solid at the inlet and outlet:

$$
\begin{aligned}
\lambda_{\mathrm{s}} \partial T_{W} / \partial x & =\varepsilon \sigma\left[T_{W}^{4}(x)-T_{\mathrm{IN}}^{4}\right] \quad \text { at } x=0, \text { and } \\
-\lambda_{\mathrm{s}} \partial T_{W} / \partial x & =\varepsilon \sigma\left[T_{W}^{4}(x)-T_{\text {OUT }}^{4}\right] \quad \text { at } x=L .
\end{aligned}
$$

Uniform profiles for the axial velocity, the species mass fractions and the temperature are specified at the inlet. At the symmetry axis $(r=0)$ and the outlet $(x=L)$ 
zero-Neumann boundary conditions were applied for all thermoscalars and the axial velocity, while the radial velocity is set to zero. Finally, no-slip conditions are used for both velocity components at $r=r_{h}$.

A staggered grid of $150 \times 24$ points (in $x$ and $r$, respectively) has been used in all simulations. Details of the steady model and the solution algorithm can be found in Dogwiler et al. (1999), Appel et al. (2002) and Schneider et al. (2006). In the transient simulations the initial temperature of the solid and of the gas volume inside the channel is set equal to the inlet gas temperature, while the integration time step is $50 \mathrm{~ms}$ [details of the transient model and the solution algorithm can be found in Schneider et al. (2008)]. The CPU time on a $2.6 \mathrm{GHz}$ Opteron processor ranges from a few hours for the steady computations to a couple of days for the transient ones; 20 such processors have been used for elaborate parametric studies.

\section{Chemical Kinetics}

The elementary heterogeneous scheme of Deutschmann et al. (2000) is used for the oxidation of $\mathrm{H}_{2} / \mathrm{CO}$ mixtures over Pt (see Table A1 in Appendix 1). This mechanism has reproduced catalytic ignition and steady combustion characteristics of $\mathrm{H}_{2}, \mathrm{CO}$ and $\mathrm{CH}_{4}$ fuels as well as mixtures of them (Deutschmann et al., 1996, 2000; Appel et al. 2002; Reinke et al., 2004). A surface site density $\Gamma=2.7 \times 10^{-9} \mathrm{~mol} / \mathrm{cm}^{2}$ is considered, simulating a polycrystalline Pt surface. Surface thermochemical data for the reversible reactions S9, S10 and S11 of Table A1 are taken from Warnatz et al. (1994).

The inclusion of gas-phase chemistry in catalytic combustion systems deserves special attention. Prior to homogeneous ignition there is typically appreciable heterogeneous fuel depletion, which reduces the already considerably fuel-lean inlet stoichiometries to ultra-lean levels. Moreover, the temperatures in catalytic combustion systems are moderate (up to $1400 \mathrm{~K}$ ) and the heterogeneously-formed major species (notably $\mathrm{H}_{2} \mathrm{O}$ ) can be very efficient collision partners in gas-phase chain terminating reactions.

On the other hand, the hetero-/homogeneous radical coupling via adsorptiondesorption reactions is generally weak (Appel et al., 2002; Reinke et al., 2005). The aforementioned factors greatly impact the aptness of homogeneous chemical reaction schemes in catalytic systems. Comparative studies of various $\mathrm{H} / \mathrm{O}$ and $\mathrm{C}_{1} / \mathrm{H} / \mathrm{O}$ mechanisms during catalytic combustion of $\mathrm{H}_{2}$ or $\mathrm{CH}_{4}$ over $\mathrm{Pt}$ have revealed significant discrepancies in their capacity to reproduce measured homogeneous ignition characteristics (ignition delays). Appel et al. (2002) have shown the aptness of the gas-phase scheme of Warnatz et al. (1996) in $\mathrm{H}_{2} /$ air hetero-/homogeneous combustion over $\mathrm{Pt}$ at atmospheric pressure.

Ongoing studies (Mantzaras et al. 2008) have also shown the aptness of the mechanism of Warnatz (2005) for $\mathrm{H}_{2}$ /air hetero-/homogeneous combustion at pressures of up to 10 bar (see Table A2). For $\mathrm{H}_{2} / \mathrm{CO}$ mixtures, the hydrogen scheme is augmented by the $\mathrm{C}_{1}$ mechanism of Warnatz et al. (1996), which has been recently tested in high-pressure $\mathrm{CH}_{4}$ /air catalytic combustion (Reinke et al., 2005, 2007). The CO-relevant part of this mechanism is also provided in Table A2. The surface and gas-phase reaction rates are evaluated with Surface CHEMKIN (Coltrin et al., 1996) and CHEMKIN (Kee et al., 1996b), respectively. 


\section{RESULTS AND DISCUSSION}

Before discussing the catalytic combustion of syngas, it is informative to firstly address the combustion of pure $\mathrm{H}_{2}$ and $\mathrm{CO}$ fuels. This facilitates the identification of the particular combustion characteristics of each fuel component and aids the subsequent discussion on the hetero-/homogeneous chemical coupling during combustion of syngas fuels with varying $\mathrm{H}_{2} / \mathrm{CO}$ compositions.

\section{Catalytic Combustion of Hydrogen/Air Mixtures}

The catalytic combustion of fuel-lean hydrogen/air mixtures is initially investigated. This section identifies key issues for reactor thermal management and for the effect of gaseous chemistry.

\section{Surface Temperatures and Impact of the Homogeneous Pathway}

Figure 2 provides the predicted catalytic $(C)$ and gas-phase $(G)$ hydrogen conversion rates as well as the wall temperature $\left(T_{W}\right)$ for atmospheric pressure $\mathrm{H}_{2}$ /air combustion in the channel geometry of Figure 1. Four different equivalence ratios are presented; in all cases the inlet velocity and temperature is $U_{\mathrm{IN}}=20 \mathrm{~m} / \mathrm{s}$ and $T_{\mathrm{IN}}=600 \mathrm{~K}$, respectively. The $G$ profiles of Figure 2 were constructed by

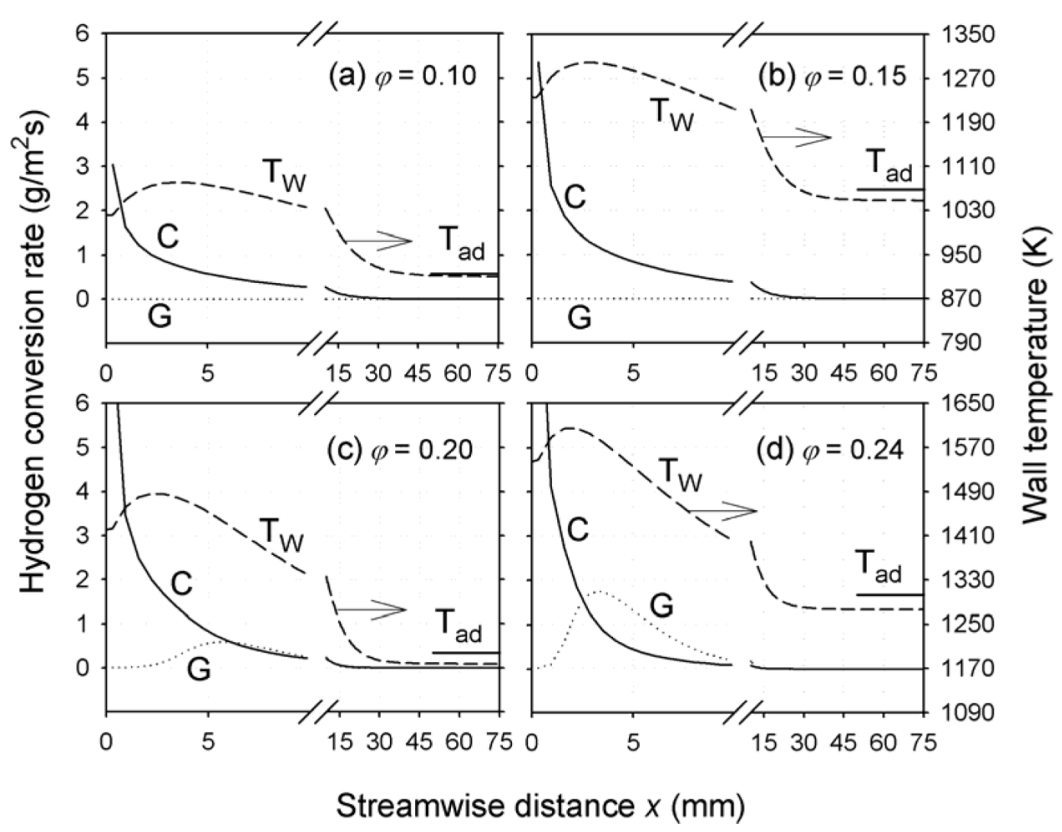

Figure 2 Computed axial profiles of catalytic ( $C$, solid lines) and gas-phase ( $G$, dotted lines) conversion rates of hydrogen, and wall temperature $\left(T_{W}\right.$, dashed lines) in the channel geometry of Figure 1 . Four $\mathrm{H}_{2} /$ air equivalence ratios are shown in (a) to (d). In all cases $p=1 \mathrm{bar}, U_{\mathrm{IN}}=20 \mathrm{~m} / \mathrm{s}$ and $T_{\mathrm{IN}}=600 \mathrm{~K}$. The horizontal lines marked $T_{\text {ad }}$ provide the adiabatic equilibrium temperature. For clarity, the first $10 \mathrm{~mm}$ are expanded. 
integrating the local volumetric gaseous reaction rates across the channel radius so as to facilitate comparisons with the catalytic surface rates. It is evident that the surface temperatures at the upstream parts of the reactor exceed substantially (by up to $300 \mathrm{~K}$ ) the adiabatic equilibrium temperatures (the latter are indicated by the lines marked $T_{\text {ad }}$ in Fig. 2).

Complete hydrogen conversion is attained in all cases at the channel exit, such that the wall temperatures far downstream are only slightly lower than $T_{\text {ad }}$ due to the imposed radiation heat losses. The superadiabatic surface temperatures are a wellknown effect in catalytic combustion of diffusionally imbalanced fuels with Lewis numbers less than unity, Le < 1 (Pfefferle and Pfefferle, 1986; Bui et al., 1996; Appel et al., 2002), the underlying reason being that fuel is transported more effectively towards the catalytic surface than heat is convected away from it. The maximum attainable surface temperature is $T_{W}=T_{\mathrm{IN}}+L e^{-2 / 3}[\Delta T]_{\mathrm{c}}$ (Mantzaras, 2006b) with $[\Delta T]_{\mathrm{c}}$ the adiabatic combustion temperature rise; thus, for fuel-lean hydrogen combustion with $L e \sim 0.3$, the temperature rise can be more than a factor of two higher than that dictated by thermodynamics. This behavior compounds catalytic combustion of hydrogen or hydrogen-rich fuels and requires careful strategies for reactor thermal management in order to attain surface temperatures tolerable by the catalyst and the reactor structure.

The contribution of the gaseous pathway is practically zero in Figure $2 a$ and $2 b$, whereas at the higher equivalence ratios of Figures $2 \mathrm{c}$ and $2 \mathrm{~d}$ homogeneous ignition is attained inside the reactor as indicated by the corresponding $G$ conversions. A usual premise in catalytic systems considers gas-phase combustion as detrimental to the catalyst integrity and hence homogeneous ignition is deemed undesirable. However, in the case of hydrogen the onset of gaseous combustion is actually beneficial as it moderates the surface temperatures.

This is illustrated in Figure 3a, whereby comparisons are shown for the $\varphi=0.24$ case of Figure $2 \mathrm{~d}$ and for the same case computed without the inclusion of gaseous chemistry. The comparisons of Figure $3 \mathrm{a}$ indicate that gas-phase chemistry decreases the surface temperatures by as much as $90 \mathrm{~K}$ and the peak temperature by $\sim 30 \mathrm{~K}$. This rather unexpected behavior has recently been observed experimentally in Appel et al. (2002) and (2005b) and also clarified therein. In fuels with $L e<1$ the flame is confined near the wall, as also shown by the $\mathrm{OH}$ maps of Figure $4 \mathrm{a}$ (referring to the case of Fig. 2d), thus shielding the catalytic surface from the hydrogen-rich channel core and reducing the heterogeneous conversion that is responsible for the superadiabatic temperatures. The confinement of the gaseous combustion near the wall has also been attested in stagnation-flow catalytic combustion of fuels with $L e<1$ (Law and Sivashinsky 1982).

It is further noted that the near-wall flame confinement leads always to combined heterogeneous and homogeneous conversions due to the reduced residence time inside the narrow gaseous combustion zone and the subsequent leakage of the hydrogen fuel towards the nearby catalytic surface (see, for example, the $C$ and $G$ curves in Figure $2 \mathrm{~d}$ at $1 \mathrm{~mm}<x<15 \mathrm{~mm}$ ). This is in contrast to methane catalytic combustion, whereby upon homogeneous ignition the dominant fuel conversion pathway is the homogeneous one (Dogwiler et al., 1999; Reinke et al., 2005).

The heterogeneous reactivity of hydrogen on $\mathrm{Pt}$ is high, leading to practically mass-transport-limited catalytic conversion at realistic reactor linear velocities. This 


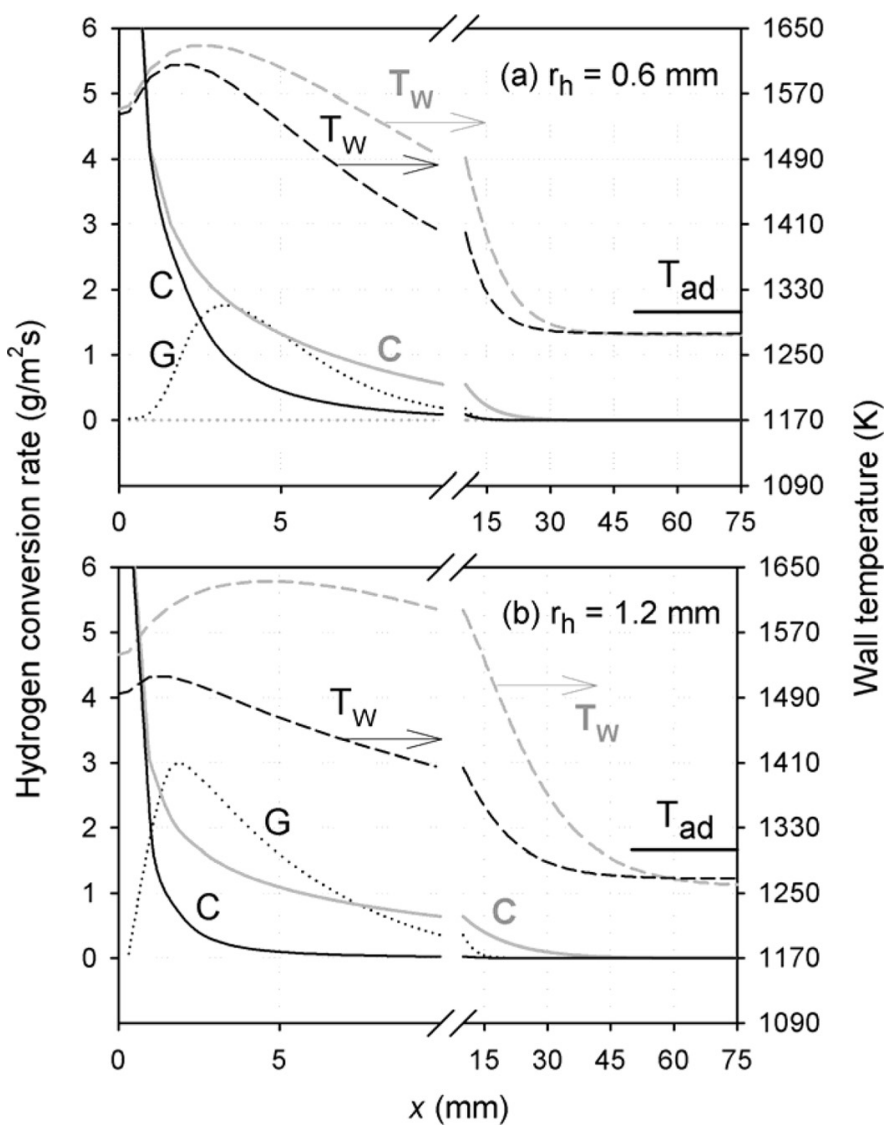

Figure 3 Computed axial profiles of catalytic ( $C$, solid lines) and gas-phase ( $G$, dotted lines) conversion rates of hydrogen, and wall temperature ( $T_{W}$, dashed lines). Black lines: heterogeneous and homogeneous chemistry included. Gray lines: only heterogeneous chemistry included. Predictions for channel radii: (a) $0.6 \mathrm{~mm}$ and (b) $1.2 \mathrm{~mm}$. In both cases $p=1 \mathrm{bar}, U_{\mathrm{IN}}=20 \mathrm{~m} / \mathrm{s}$ and $T_{\mathrm{IN}}=600 \mathrm{~K}$. For clarity, the first $10 \mathrm{~mm}$ are expanded.

is illustrated by the very low near-wall levels of hydrogen in Figure 4b (already from the beginning of the channel) and also by the high catalytic conversion rates at the channel entry (see the $C$ curves in Fig. 2 at $x \approx 0$ ). It is further clarified that the magnitude of the catalytic conversion at $x \approx 0$ is always finite (see Fig. 2). The catalytic ignition or light-off length (using the rather strict definition as the axial position where the hydrogen wall levels drop to $10 \%$ of the corresponding centerline values) is, for all cases, less than $2.5 \mathrm{~mm}$.

The computations of Figure 2 indicate that homogeneous combustion can be important at realistically large channel confinements (i.e., small radii) with $r_{h}=0.6 \mathrm{~mm}$. An increase of the channel radius enhances the contribution of the gaseous pathway as shown in Figure $3 \mathrm{~b}$ with $r_{h}=1.2 \mathrm{~mm}$. In the wider channel of Figure $3 \mathrm{~b}$ the moderating impact of gaseous chemistry on the surface temperatures is stronger and, moreover, the peak surface temperature is about $100 \mathrm{~K}$ lower than that of the narrower channel (Fig. 3a). The interplay of the heterogeneous and 


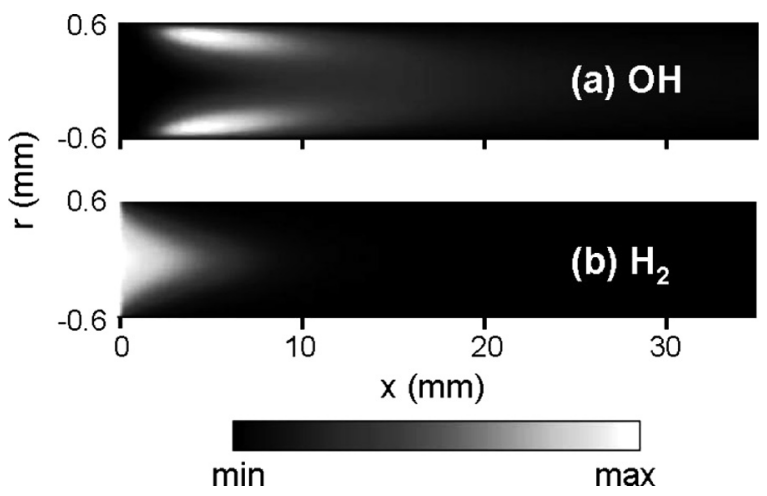

Figure 4 Computed 2D distributions of species mass fractions for the case of Figure 2d: (a) $\mathrm{OH}$, (b) $\mathrm{H}_{2}$. For clarity, only the first $35 \mathrm{~mm}$ of the channel are shown. The $\mathrm{OH}$ ranges from 0.0 to $9.95 \times 10^{-4}$ and the $\mathrm{H}_{2}$ from 0.0 to $6.99 \times 10^{-3}$.

homogeneous pathways and its coupling to fluid mechanical transport is hence quite rich, suggesting certain reactor design procedures. For example, wider channels appear preferable for moderating the surface temperatures during hydrogen and hydrogen-rich catalytic combustion.

The reduction of the surface-to-volume ratio when employing wider channels is not critical since the catalytic conversion is anyway high (given the very large diffusivity of hydrogen and its high catalytic reactivity). Nonetheless, increasing the hydraulic diameter of the catalytic channels may not be sufficient to control the temperatures to tolerable levels. Given the fact that syngas compositions with corresponding adiabatic equilibrium temperatures of $\sim 1400 \mathrm{~K}$ are required for power generation, Figures 2 and 3 suggest that additional passive cooling measures may be needed. Such measures include honeycomb reactors with alternately coated channels (sequence of catalytically active and inactive channels) as in Carroni et al. (2003) and Appel et al. (2005a). The passive cooling approach necessitates a CST combustion methodology, i.e., the inclusion of a post-catalyst flame zone to complete the conversion of the hydrogen flowing through the non-catalytic channels.

\section{Effect of Pressure}

The impact of pressure on the underlying hetero-/homogeneous processes is of key interest in many industrial devices. Figure 5 provides catalytic and gas-phase hydrogen conversion rates and surface temperatures at 5 and 15 bar. The other conditions are the same as in the $p=1$ bar case of Figure 2c with the exception of the inlet velocity, which is reduced with increasing pressure so as to maintain the same mass throughput. Comparison of Figures $2 \mathrm{c}$ and 5 indicates that gaseous combustion is favored at high pressures. As explained in the previous section, an enhanced homogeneous conversion moderates the surface temperatures; therefore, the peak temperatures in Figure 5 are lower than the peak temperature of Figure $2 \mathrm{c}$ ( $p=1$ bar).

To address the hetero-/homogeneous chemistry coupling at high pressures, a brief discussion on the pure homogeneous ignition characteristics of hydrogen is presented next. Ignition delay times are provided in Figure 6 for a $\varphi=0.28 \mathrm{H}_{2} /$ air 


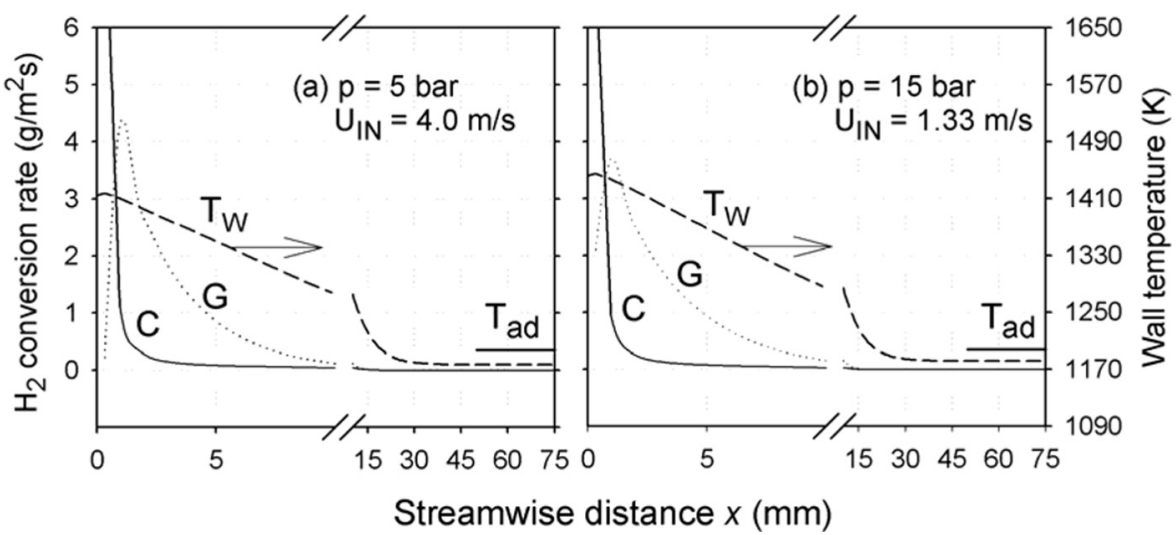

Figure 5 Computed axial profiles of catalytic ( $C$, solid lines) and gaseous ( $G$, dotted lines) conversion rates of $\mathrm{H}_{2}$, and wall temperature ( $T_{W}$, dashed lines) for (a) $p=5$ bar and (b) $p=15$ bar. In both cases $T_{\mathrm{IN}}=600 \mathrm{~K}$ and $\phi=0.20$. The inlet velocity, $U_{\mathrm{IN}}$, is such that the product $p U_{\mathrm{IN}}$ is constant (same mass throughput).

mixture at different pressures. The gas-phase ignition delays were computed using the SENKIN package of CHEMKIN (Lutz et al., 1996) at various fixed temperatures in order to mimic the presence of the hot catalytic wall that heats the flowing reacting gas (the ignition delays were defined as the times required for hydrogen to drop to $50 \%$ of its initial concentration). At a moderate temperature of $1000 \mathrm{~K}$ the gaseous reactivity decreases (the ignition delay increases) with rising pressure and then remains

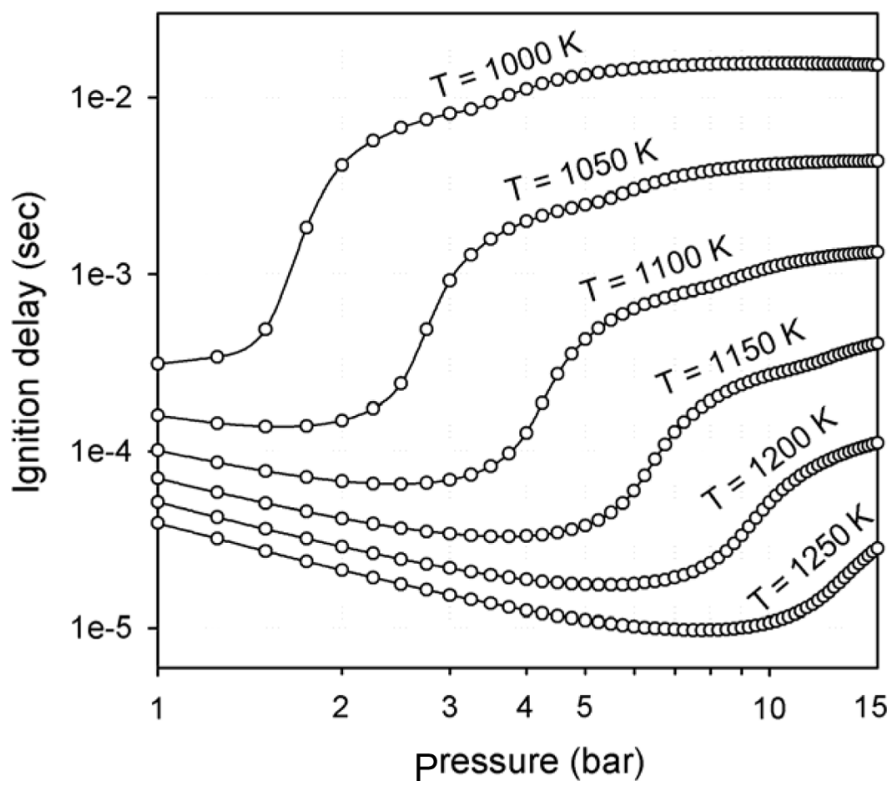

Figure 6 Predicted gas-phase ignition delays as a function of pressure for a $\phi=0.28$ hydrogen/air mixture at different temperatures. 


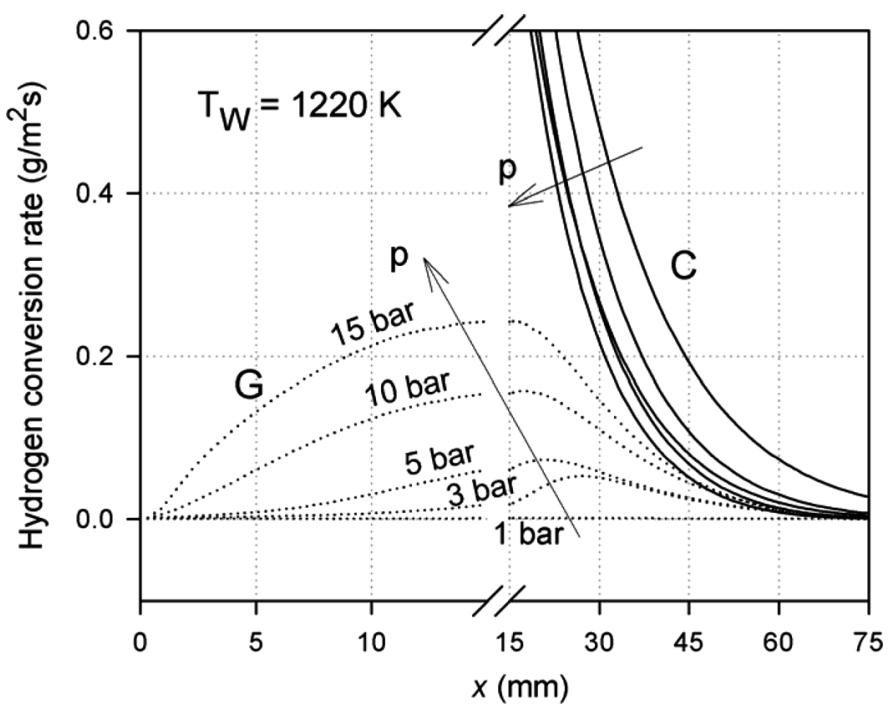

Figure 7 Computed axial profiles of catalytic ( $C$, solid lines) and gas-phase ( $G$, dotted lines) conversion rates of hydrogen for various pressures. The wall temperature is fixed to $T_{W}=1220 \mathrm{~K}, \phi=0.24$ and $T_{\mathrm{IN}}=600 \mathrm{~K}$. The inlet velocity is $U_{\mathrm{IN}}=3.33 \mathrm{~m} / \mathrm{s}$ at 15 bar, while at other pressures it is such that $p U_{\mathrm{IN}}=$ constant.

practically constant for $p>8$ bar. At higher temperatures the reactivity initially increases with rising pressure and then drops, with the turning point shifted to higher pressures for higher temperatures. The behavior shown in Fig. 6 is also reproduced (at least qualitatively) with other gas-phase mechanisms (Li et al. 2003). The implication for high-pressure catalytic combustion is that for sufficiently low channel wall temperatures the onset of gas-phase ignition is suppressed with rising pressure.

This has also been verified in recent experiments (Mantzaras et al., 2008) carried out in a rectangular Pt-coated catalytic reactor with a transverse separation of $7 \mathrm{~mm}$. However, in practical catalytic reactors with narrow channels of $\sim 1 \mathrm{~mm}$ in hydraulic diameter, the aforementioned reduction of the gaseous reactivity with rising pressure at low temperatures becomes irrelevant: gas-phase chemistry is altogether absent (even at $p=1$ bar) due to the increased surface-to-volume ratios that in turn allow for complete hydrogen catalytic consumption during the elongated gas-phase induction zone. It is emphasized that the catalytic conversion is aided by the large diffusivity of hydrogen and its high reactivity on $\mathrm{Pt}$ even at moderate surface temperatures.

At higher temperatures, however, the previous picture is reversed and an increase in pressure promotes gas-phase ignition. This is further illustrated in the computations of Figure 7, carried out in the geometry of Figure 1. Contrary to the predictions of Figure 5, the wall temperature in Figure 7 is fixed to $T_{W}=1220 \mathrm{~K}$ in order to decouple thermal from chemical effects; the mass throughput is again fixed at all pressures. For the wall temperature of Figure 7, it is clearly seen that homogeneous ignition is favored at higher pressures. The expected behavior after the turning point of Figure 6 (pressures greater than $\sim 10$ bar) is not evident in Figure 7, possibly due to the fact that homogeneous ignition is already achieved at the channel entry for $p=10$ bar. This issue is of prime interest for gas turbines and requires further investigation. 


\section{Catalytic Ignition}

The foregoing steady computations cannot address the issue whether the obtained stable burning solutions are feasible for a particular set of initial conditions (a realistic condition is to have an initial solid temperature equal to the gas inlet temperature). Therefore, transient catalytic ignition (light-off) computations have also been carried out for the conditions of Figure 2 and for inlet temperatures lower than $600 \mathrm{~K}$. Equivalence ratios of 0.20 and 0.24 are considered, i.e., mixtures with sufficient exothermicity for power generation systems. The light-off time is defined as the time required for the solid to reach within $5 \mathrm{~K}$ of its corresponding steady-state temperature, provided that the steady solution corresponds to a vigorous burning state (wall emperatures close to $T_{\text {ad }}$ or greater) and not to a weakly reacting state.

Characteristically, for $p=10 \mathrm{bar}, U_{\mathrm{IN}}=2 \mathrm{~m} / \mathrm{s}, T_{\mathrm{IN}}=600 \mathrm{~K}$ and $\varphi=0.20$, the steady solution is reached after $0.2 \mathrm{~s}$; when the inlet temperature is reduced to $380 \mathrm{~K}$, the corresponding time increases to $3.2 \mathrm{~s}$. It is clarified that the computed light-off times for the given $T_{\mathrm{IN}}$ are only indicative of the easiness of catalytic ignition since they also depend on specific reactor and catalyst parameters such as linear velocity, geometry, heat loss mechanisms, catalyst dispersion, etc. Nonetheless, for the particular reactor parameters of this study (that resemble those encountered in gasturbine systems) ignition could always be achieved for inlet temperatures in the range of 360 to $380 \mathrm{~K}$. The high catalytic reactivity of hydrogen appears, at a first instance, attractive for the catalytic combustion of syngas. Detailed transient light-off simulations will be presented in the syngas combustion section.

In summary, hydrogen catalytic combustion can be initiated at industriallyrelevant linear velocities and pressures, at inlet temperatures as low as $360 \mathrm{~K}$. The catalytic conversion becomes transport-limited within a short reactor length $(\sim 2.5 \mathrm{~mm})$. Of major concern in hydrogen catalytic combustion is the reactor thermal management due to the attained superadiabatic surface temperatures. Gasphase combustion cannot be ignored, particularly at elevated pressures, and temperatures even at industrially-relevant large geometric reactor confinements. On the other hand, the presence of gaseous combustion moderates the reactor temperatures by suppressing the heterogeneous conversion that drives the aforementioned superadiabaticity.

\section{Catalytic Combustion of CO/Air Mixtures}

The catalytic combustion of $\mathrm{CO} /$ air mixtures is considered next. The analysis in this section is much simplified compared to that of hydrogen due to the absence of homogeneous chemistry (gas-phase combustion of $\mathrm{CO}$ cannot be initiated in dry air, at the temperatures of interest, without the presence of moisture or hydrogen (Glassman, 1996)) and also due to the nearly diffusionally neutral transport properties of CO.

Streamwise profiles of computed catalytic $\mathrm{CO}$ conversion rates and surface temperatures are provided in Figure 8 for various stoichiometries, $U_{\mathrm{IN}}=20 \mathrm{~m} / \mathrm{s}$, $T_{\mathrm{IN}}=600 \mathrm{~K}$ and $p=1 \mathrm{bar}$. The surface temperatures never exceed the adiabatic equilibrium values, thus greatly simplifying the reactor design. For the conditions of Figure 8, catalytic ignition is achieved at $x \approx 3.5 \mathrm{~mm}$ for $\varphi=0.10$, and at $x \approx 1.6 \mathrm{~mm}$ for $\varphi=0.24$. The shorter light-off distance at richer stoichiometries is an outcome of 


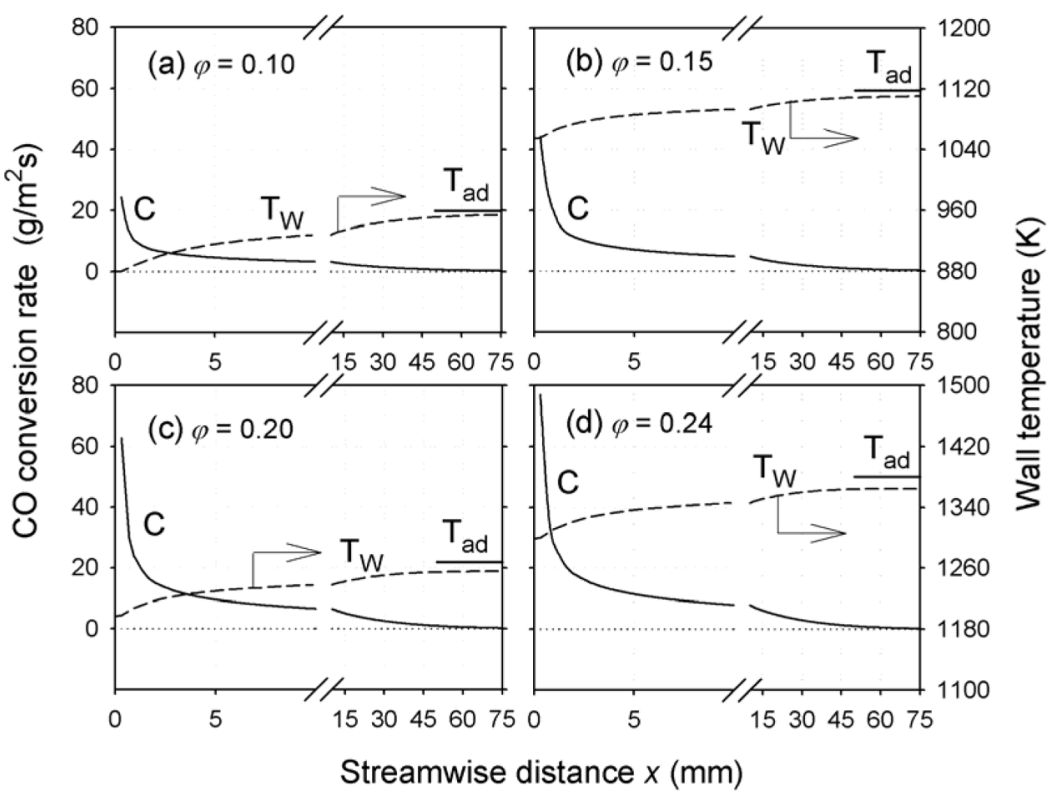

Figure 8 Computed axial profiles of catalytic ( $C$, solid lines) conversion rates of $C O$, and wall temperature ( $T_{W}$, dashed lines). Four $\mathrm{CO} /$ air equivalence ratios are shown. In all cases $p=1 \mathrm{bar}, U_{\mathrm{IN}}=20 \mathrm{~m} / \mathrm{s}$ and $T_{\mathrm{IN}}=600 \mathrm{~K}$. The horizontal lines marked $T_{\text {ad }}$ provide the adiabatic equilibrium temperature. For clarity, the first $10 \mathrm{~mm}$ are expanded.

combined chemical and thermal effects (i.e., reaction exothermicity) during steady combustion and should not be confused with the behavior reported in catalytic ignition studies. In transient catalytic ignition studies (Deutschmann et al., 1996), chemical effects dominate since the temperature is practically constant over the induction zone; therein $\mathrm{CO}$ self-inhibits its ignition through excessive surface coverage of $\mathrm{CO}(\mathrm{s})$ blocking the adsorption of oxygen. The same type of self-inhibition also controls hydrogen catalytic ignition, whereby $\mathrm{H}(\mathrm{s})$ also blocks the adsorption of oxygen.

When the pressure is increased from 1 to 15 bar and the mass throughput is kept fixed, the fuel conversion and surface temperatures virtually collapse onto each other (see Figs. 9 and 8c). This is because under mass-transport-limited catalytic operation, and in the absence of gaseous chemistry, the only controlling parameter in channel-flow combustion is the Reynolds number (Mantzaras and Benz, 1999; Mantzaras et al., 2000), which is fixed for a given mass throughput $(\rho U)_{\text {IN }}$.

Parametric transient studies have shown that for the operating conditions of Figures 8 and 9 and for the power-generation-relevant stoichiometries of $\varphi=0.20$ and 0.24 , the minimum inlet temperatures required for catalytic ignition range between 650 and $700 \mathrm{~K}$. For example, when $p=10$ bar, $U_{\mathrm{IN}}=2 \mathrm{~m} / \mathrm{s}, \varphi=0.20$ and $T_{\mathrm{IN}}=700 \mathrm{~K}$, the corresponding light-off time is $4.5 \mathrm{~s}$ (catalytic ignition of $\mathrm{CO}$ and its comparison with $\mathrm{CO} / \mathrm{H}_{2}$ ignition characteristics will be presented in the forthcoming syngas section). Carbon monoxide is thus less reactive than hydrogen on $\mathrm{Pt}$, suggesting that the addition of the latter may aid the ignition of the former. It is noted that for certain metal oxide catalysts the oxidation reactivity of $\mathrm{CO}$ can be actually higher than that of 


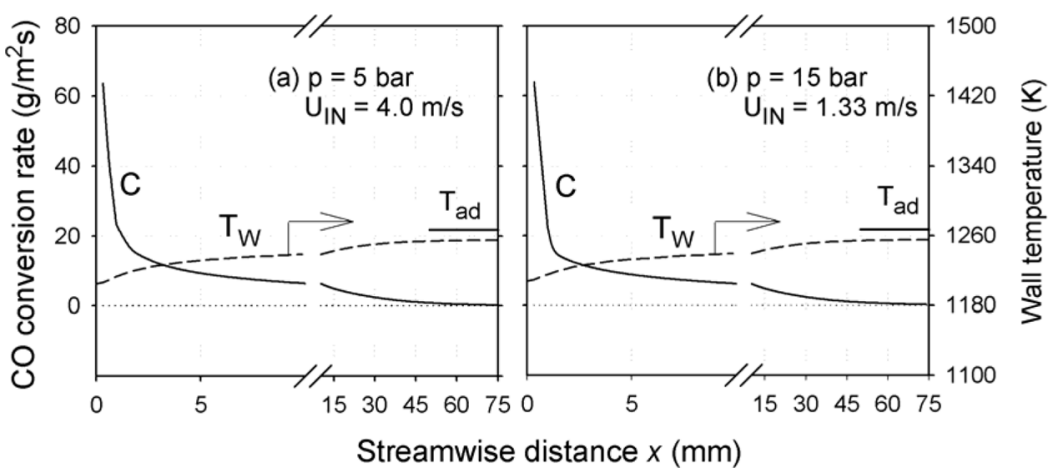

Figure 9 Computed axial profiles of catalytic ( $C$, solid lines) conversion rates of $\mathrm{CO}$ and wall temperature ( $T_{W}$, dashed lines) for (a) $p=5$ bar and (b) $p=15$ bar. In both cases $T_{\mathrm{IN}}=600 \mathrm{~K}$ and $\phi=0.20$. The inlet velocity $U_{\mathrm{IN}}$ is such that the product $p U_{\mathrm{IN}}$ is constant.

$\mathrm{H}_{2}$ (Groppi et al., 1996). Although this property may appear attractive for particular syngas compositions with large $\mathrm{CO}$ content, care must be exercised in certifying the aptness of such catalysts at the high linear velocities pertinent to practical systems.

\section{Catalytic Combustion of Syngas ( $\mathrm{H}_{2}$ and Co Mixtures)}

The hetero-/homogeneous chemical coupling of $\mathrm{H}_{2}$ and $\mathrm{CO}$ is discussed first, followed by reactor thermal management issues and, finally, by transient light-off studies of syngas fuels.

\section{Hetero-/Homogeneous Chemistry Coupling}

To isolate thermal from chemical effects, initial computations have been carried out in the geometry of Figure 1 at fixed wall temperatures. Different $\mathrm{H}_{2} / \mathrm{CO} /$ air mixtures were examined, having a combined $\mathrm{H}_{2}$ and $\mathrm{CO}$ volumetric content of $7.75 \%$. To identify the chemical impact of the added CO, additional computations have also been performed by replacing the $\mathrm{CO}$ component with a fictitious species $\mathrm{CO}^{*}$ that had the same thermodynamic and transport properties as $\mathrm{CO}$, but did not participate in any heterogeneous or homogeneous chemical reaction.

Figure 10 provides the catalytic $(C)$ and gaseous $(G)$ hydrogen and carbon monoxide conversion rates (black lines) at four different wall temperatures for a $\mathrm{H}_{2} / \mathrm{CO} /$ air mixture with $7.25 \%$ vol. $\mathrm{H}_{2}$ and $0.5 \%$ vol. $\mathrm{CO}, p=10$ bar, $U_{\mathrm{IN}}=2 \mathrm{~m} / \mathrm{s}$, $T_{\mathrm{IN}}=600 \mathrm{~K}$; in the same figure plots are also given for a corresponding $\mathrm{H}_{2} / \mathrm{CO}^{*} / \mathrm{air}$ mixture in terms of the relevant $C$ and $G$ hydrogen conversion rates (gray lines). For wall temperatures of $1300 \mathrm{~K}$ and $800 \mathrm{~K}$ (Fig. 10a, 10b)), the hydrogen $C$ and $G$ curves of the $\mathrm{H}_{2} / \mathrm{CO} /$ air and $\mathrm{H}_{2} / \mathrm{CO}^{*} /$ air mixtures virtually collapse on each other. Homogeneous combustion is present at $T_{W}=1300 \mathrm{~K}$ as manifested by the $\mathrm{H}_{2}$ and $\mathrm{CO}$ gaseous conversion curves. The gaseous conversion of hydrogen is practically unaffected by the presence of $\mathrm{CO}$ and its accompanying gas-phase or catalytic chemistry. 


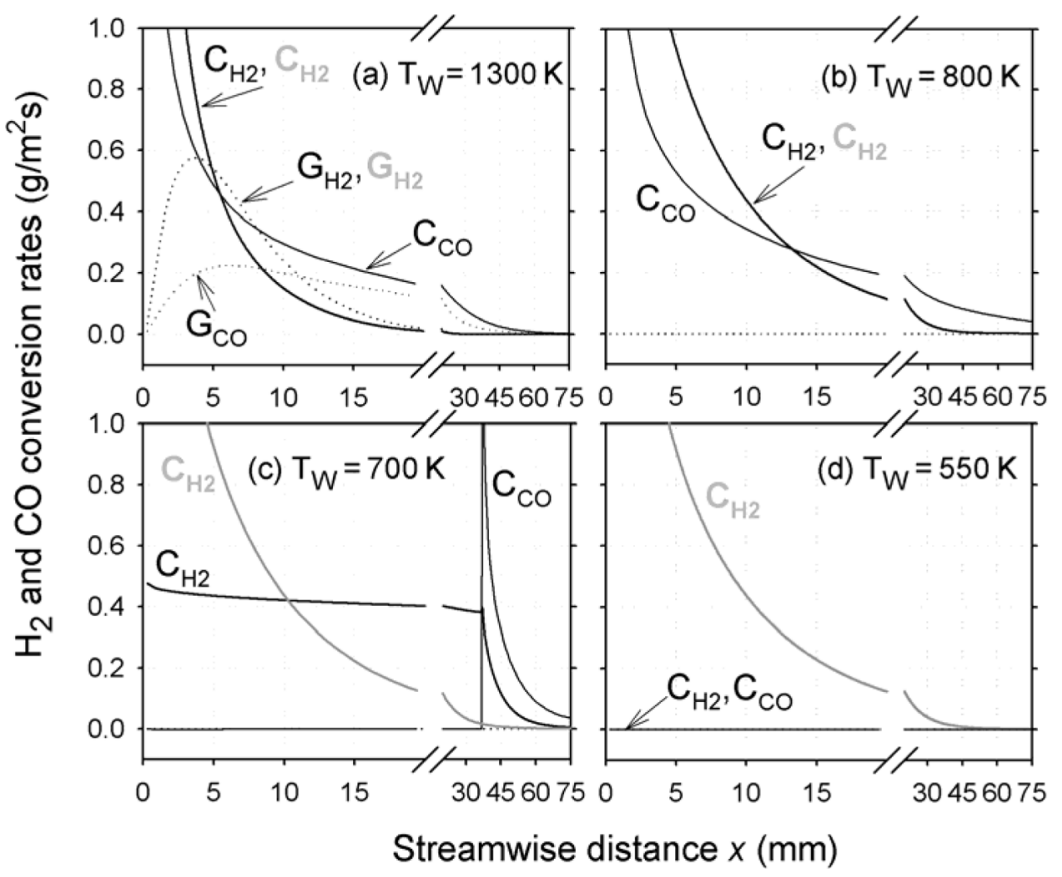

Figure 10 Computed axial profiles of catalytic ( $C$, solid lines) and gaseous $(G$, dotted lines) conversion rates of $\mathrm{CO}$ and $\mathrm{H}_{2}$, for four fixed wall temperatures. $\mathrm{H}_{2} / \mathrm{CO} /$ air mixture with $7.25 \% \mathrm{H}_{2}$ and $0.5 \%$ $\mathrm{CO}$ vol., $p=10 \mathrm{bar}, U_{\mathrm{IN}}=2 \mathrm{~m} / \mathrm{s}$ and $T_{\mathrm{IN}}=600 \mathrm{~K}$ (black lines). The $C$ and $G$ conversions of $\mathrm{H}_{2}$ are also provided when $\mathrm{CO}$ is replaced by inert $\mathrm{CO}^{*}$ (gray lines). In (a) and (b) the black and gray $C_{\mathrm{H} 2}$ lines coincide. For clarity, the first $20 \mathrm{~mm}$ are expanded.

This is because the homogeneous combustion of $\mathrm{CO}$ is initiated by $\mathrm{OH}$ radical attack on $\mathrm{CO}$ and as such it does not deplete the hydrogen fuel at any noticeable extent (the initiation step $\mathrm{OH}+\mathrm{CO}=\mathrm{CO}_{2}+\mathrm{H}$ is followed by the attack of $\mathrm{H}$ on $\mathrm{O}_{2}$ producing $\mathrm{OH}$; therefore, $\mathrm{OH}$ serves as a homogeneous catalyst which is not over-depleted). Moreover, the catalytic CO chemistry does not affect the homogeneous combustion of hydrogen since the hetero-/homogeneous radical coupling (notably via $\mathrm{O}$ in the case of $\mathrm{CO}$ fuel) is weak and also there are no major products in $\mathrm{CO}$ combustion that can couple as effectively as $\mathrm{H}_{2} \mathrm{O}$ with the gaseous chemistry of hydrogen (Appel et al. 2002).

On the other hand, the gaseous combustion of $\mathrm{CO}$ is crucially dependent on the presence of hydrogen. The $\mathrm{OH}$ radicals that initiate the gaseous combustion of $\mathrm{CO}$ are provided by the hydrogen homogeneous reaction pathway; the hydrogen catalytic pathway itself is a poor producer of radicals so as to appreciably affect the gaseous combustion of CO. Finally, the heterogeneous and homogeneous pathways convert $\mathrm{CO}$ in parallel over most of the channel length (Fig. 10a), since at the moderate temperatures of catalytic combustion systems the gaseous oxidation of $\mathrm{CO}$ is slow.

The catalytic conversion rate of hydrogen is unaffected by the presence of $\mathrm{CO}$ for surface temperatures at least as low as $800 \mathrm{~K}$ (see Figs. 10a, 10b). At 
sufficiently high temperatures most of the surface is covered by $\mathrm{O}(\mathrm{s})$ and free sites (see Fig. 11a). The $\mathrm{H}_{2} / \mathrm{CO}^{*} /$ air computations (not shown in Fig. 11) reveal practically the same coverage for $\mathrm{O}(\mathrm{s})$ and $\mathrm{Pt}(\mathrm{s})$. The free site coverage is thus sufficient to accommodate the heterogeneous oxidation of both fuel components, which proceeds without any appreciable chemical interaction between $\mathrm{H}_{2}$ and $\mathrm{CO}$. However, as the wall temperature is reduced to $700 \mathrm{~K}$ or less, there is a marked deviation in the hydrogen conversion rates (Fig. 10c). For a substantial reactor length (down to $x \approx 37 \mathrm{~mm}$ ), $\mathrm{CO}$ inhibits the catalytic conversion of hydrogen as seen by comparing the black and gray $C_{\mathrm{H} 2}$ curves of Fig. 10c; over this reactor extent, the main surface coverage is $\mathrm{CO}(\mathrm{s})$ (see Fig. 11b), greatly reducing the $\mathrm{O}(\mathrm{s})$ and free sites.

At $x \approx 37 \mathrm{~mm}$, there is an abrupt catalytic ignition of $\mathrm{CO}$ that depletes rapidly this component thus reducing $\mathrm{CO}(\mathrm{s})$ and increasing the $\mathrm{O}(\mathrm{s})$ and $\mathrm{OH}(\mathrm{s})$ coverage. Complete conversion of hydrogen is attained at the reactor exit such that the areas under the black and gray $C_{\mathrm{H} 2}$ curves in Fig. 10c are equal. At even lower surface temperatures (Fig. 10d, $T_{W}=550 \mathrm{~K}$ ), the $\mathrm{CO}(\mathrm{s})$ blocking dominates due to the high sticking coefficient of $\mathrm{CO}$, thus suppressing not only the catalytic conversion of

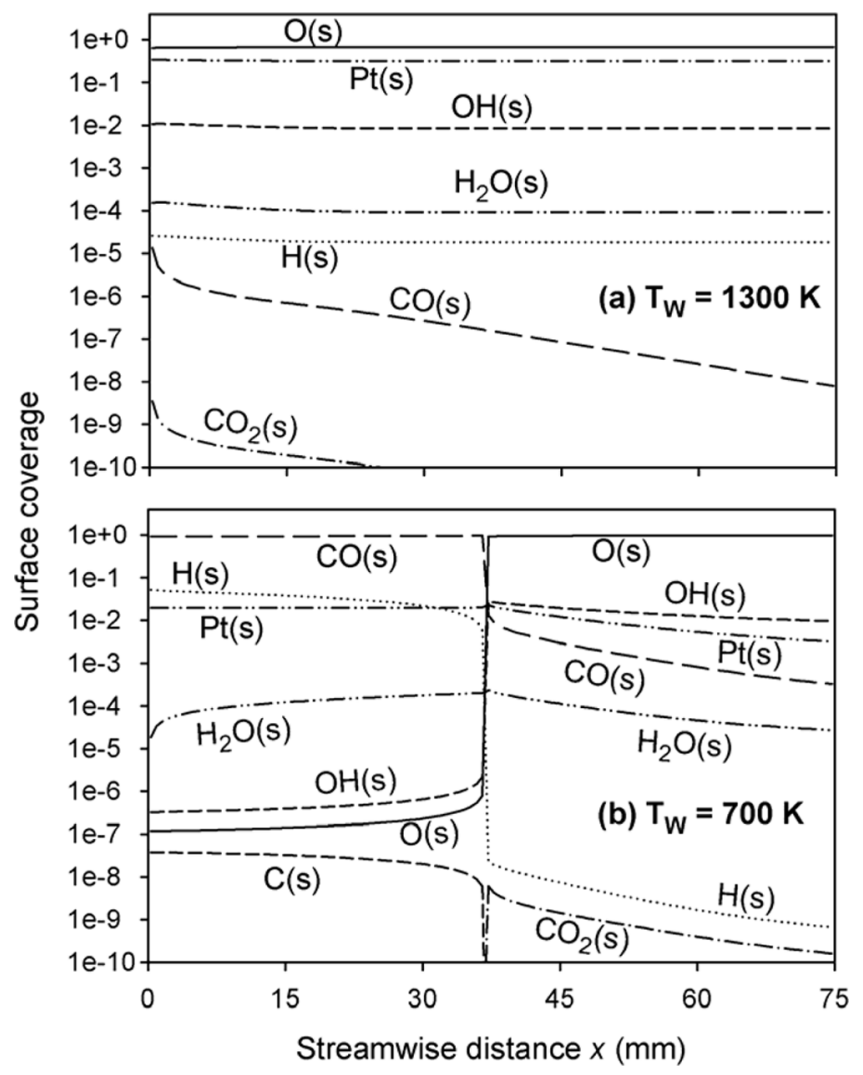

Figure 11 Surface coverage for wall temperatures of (a) $1300 \mathrm{~K}$ and (b) $700 \mathrm{~K}$. The other parameters are as in Figure 10. 
hydrogen (which would otherwise occur even at this low surface temperature in the absence of $\mathrm{CO}$ ) but also of $\mathrm{CO}$ itself.

Figure 10 has indicated that for surface temperatures below about $700 \mathrm{~K}$ carbon monoxide suppresses the hydrogen catalytic conversion even for a small $0.5 \%$ vol. addition. It turns out that higher $\mathrm{CO}$ dilutions do not alter appreciably this limit temperature. Predictions are shown in Figure 12 for $\mathrm{H}_{2} / \mathrm{CO} /$ air and $\mathrm{H}_{2} / \mathrm{CO}^{*} /$ air mixtures having $3.75 \%$ vol. $\mathrm{H}_{2}$ and $4.00 \%$ vol. $\mathrm{CO}$ (or $\mathrm{CO}^{*}$ ), the other operating conditions being the same as in Figure 10. Similar to the observations of Fig. 10, there is no noticeable coupling between the $\mathrm{CO}$ and $\mathrm{H}_{2}$ catalytic chemistries at $T_{W}=1300 \mathrm{~K}$ and $800 \mathrm{~K}$ (Fig. $12 \mathrm{a}, 12 \mathrm{~b}$ ); however, at $T_{W}=700 \mathrm{~K}$ (Fig. 12c) a considerable suppression of the $\mathrm{H}_{2}$ catalytic conversion is again evident.

Although this suppression is stronger than the corresponding one of Figure 10c, the transition temperature appears to increase only mildly even with a significant increase of the $\mathrm{CO}$ content. Furthermore, at high wall temperatures (Fig. 12a) gaseous combustion of $\mathrm{CO}$ is initiated despite the minimal gas-phase hydrogen conversion; nonetheless, the radicals needed for the gas-phase $\mathrm{CO}$ combustion are still homogeneously-produced. Computations at pressures of 1 and 15 bar (maintaining

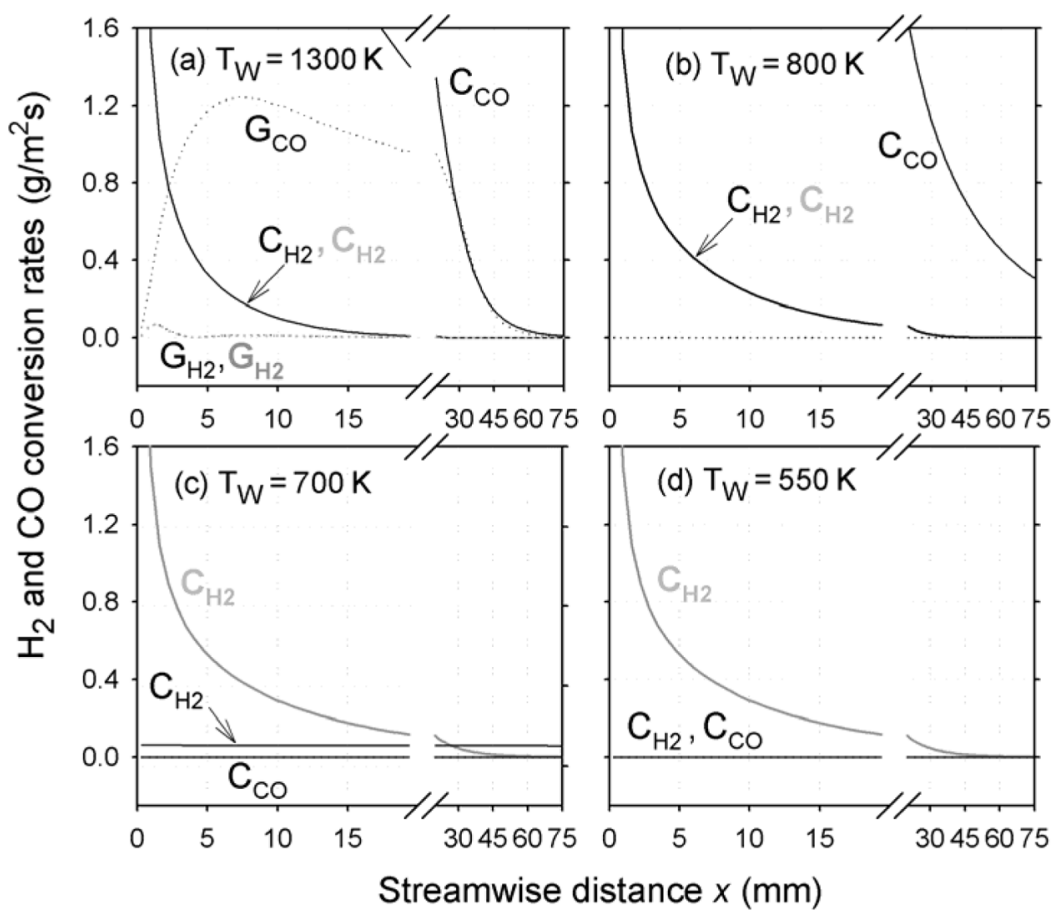

Figure 12 Computed axial profiles of catalytic ( $C$, solid lines) and gaseous ( $G$, dotted lines) conversion rates of $\mathrm{CO}$ and $\mathrm{H}_{2}$, for four fixed wall temperatures. $\mathrm{H}_{2} / \mathrm{CO} /$ air mixture with $3.75 \% \mathrm{H}_{2}$ and $4 \% \mathrm{CO}$ vol., $p=10 \mathrm{bar}, U_{\mathrm{IN}}=2 \mathrm{~m} / \mathrm{s}$ and $T_{\mathrm{IN}}=600 \mathrm{~K}$ (black lines). The $C$ and $G$ conversions of hydrogen are also provided when $\mathrm{CO}$ is replaced by inert $\mathrm{CO}^{*}$ (gray lines). In (a) and (b) the black and gray $C_{\mathrm{H} 2}$ lines coincide. For clarity, the first $20 \mathrm{~mm}$ are expanded. The $y$-axis scale is chosen so as to facilitate comparisons of both $\mathrm{H}_{2}$ and $\mathrm{CO}$ conversions: at $x \sim 0, C_{\mathrm{CO}}$ reaches $\sim 33 \mathrm{~g} / \mathrm{m}^{2} \mathrm{~s}$ in (a) and $\sim 28 \mathrm{~g} / \mathrm{m}^{2} \mathrm{~s}$ in (b). 
the same mass throughput as in Fig. 10) have further indicated that the transition temperature of $\sim 700 \mathrm{~K}$ is independent of pressure. Finally, above the transition temperature of $\sim 700 \mathrm{~K}$ and for nearly equimolar $\mathrm{H}_{2} / \mathrm{CO}$ mixtures, the catalytic conversion of $\mathrm{H}_{2}$ is accomplished at shorter axial distances compared to that of $\mathrm{CO}$ (Fig. 12(a, b)) due to the high diffusivity of the former species.

In summary, at reactor temperatures above ca. $700 \mathrm{~K}$ the chemical coupling between the hydrogen and carbon monoxide catalytic pathways is minimal. At sufficiently high temperatures where gas-phase combustion is present, the homogeneous chemistry of hydrogen is practically unaffected by the presence of $\mathrm{CO}$ while the $\mathrm{CO}$ gaseous pathway is crucially dependent on gas-phase hydrogen chemistry. At surface temperatures below $700 \mathrm{~K}$ there is a strong catalytic chemistry coupling between $\mathrm{H}_{2}$ and $\mathrm{CO}$, with the latter species inhibiting the conversion of the former.

\section{Surface Temperatures}

Steady computations are carried out in order to determine the maximum surface temperatures attained during catalytic combustion of $\mathrm{H}_{2} / \mathrm{CO} /$ air mixtures. Axial profiles of the computed catalytic and gaseous conversion rates as well as of the surface temperatures are presented in Figure 13 for syngas fuels with various $\mathrm{H}_{2} / \mathrm{CO}$ compositions. In all cases of Figure $13, p=1 \mathrm{bar}, T_{\mathrm{IN}}=600 \mathrm{~K}$,

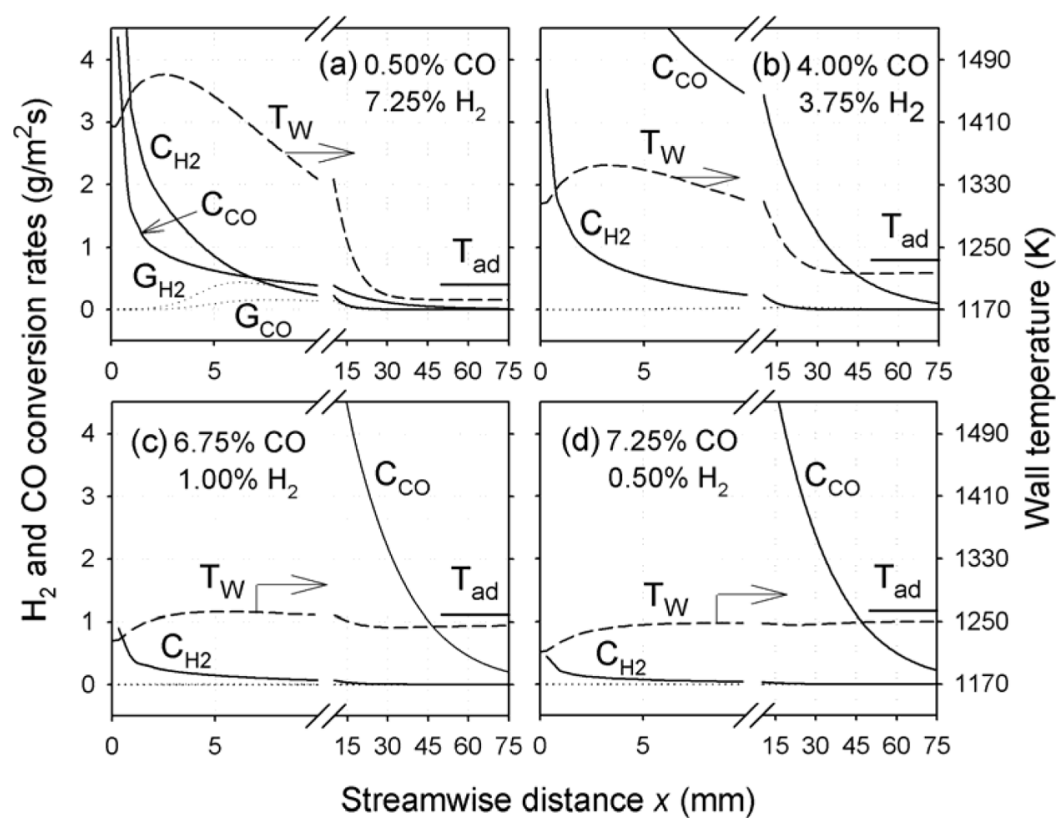

Figure 13 Computed axial profiles of catalytic $(C$, solid lines) and gas-phase $(G$, dotted lines) conversion rates of $\mathrm{H}_{2}$ and $\mathrm{CO}$, and wall temperature ( $T_{W}$, dashed lines). $\mathrm{H}_{2} / \mathrm{CO}$ /air mixtures with four different $\mathrm{H}_{2} / \mathrm{CO}$ compositions. In all cases $p=1 \mathrm{bar}, U_{\mathrm{IN}}=20 \mathrm{~m} / \mathrm{s}$ and $T_{\mathrm{IN}}=600 \mathrm{~K}$. The horizontal lines marked $T_{\text {ad }}$ provide the adiabatic equilibrium temperature. For clarity, the first $10 \mathrm{~mm}$ are expanded. The $y$-axis scale is chosen so as to facilitate comparisons of both $\mathrm{H}_{2}$ and $\mathrm{CO}$ conversions: at $x \sim 0, C_{\mathrm{CO}}$ reaches $\sim 34 \mathrm{~g} / \mathrm{m}^{2} \mathrm{~s}$ in (b), $\sim 55 \mathrm{~g} / \mathrm{m}^{2} \mathrm{~s}$ in (c), and $\sim 60 \mathrm{~g} / \mathrm{m}^{2} \mathrm{~s}$ in (d). 
$U_{\mathrm{IN}}=20 \mathrm{~m} / \mathrm{s}$, while the sum of the $\mathrm{H}_{2}$ and $\mathrm{CO}$ volumetric compositions is fixed at $7.75 \%$. Similar plots are provided in Figure 14 for two $\mathrm{H}_{2} / \mathrm{CO}$ compositions, $T_{\mathrm{IN}}=600 \mathrm{~K}$ and $p=10 \mathrm{bar}$. For hydrogen contents as low as $1 \%$ vol., superadiabatic surface temperatures are attained at the upstream sections of the reactor.

At atmospheric pressure, the gaseous chemistry of both fuel components is noticeable only at the highest hydrogen concentration (Fig. 13a). On the other hand, at elevated pressures the gaseous pathway becomes more significant and its impact extends to lower hydrogen contents (compare Figs. 14 and 13(b, c)). The presence of hydrogen gaseous combustion at $p=10$ bar moderates the surface temperatures along most of the reactor length as seen in Figures 14a and 13b (the peak temperature remains relatively unaffected because the light-off length is somewhat shorter in the high-pressure cases as manifested by the corresponding higher hydrogen catalytic conversion rates at $x \approx 0$ ).

In addition, the gas-phase combustion of $\mathrm{CO}$ accelerates substantially with increasing pressure, although its presence does not affect the surface temperatures. For reactors designed to operate without excessive surface heat losses, the presence of $\mathrm{CO}$ gaseous combustion does not pose a thermal management concern. In addition, the homogeneous consumption of $\mathrm{CO}$ at high pressures may be desirable in accomplishing the conversion of this species at rates faster -and hence at shorter reactor lengths- than those dictated by heterogeneous mass transport limitations.

The volumetric substitution of $\mathrm{H}_{2}$ by $\mathrm{CO}$ lowers the surface temperatures (Fig. 13) despite the fact that the molar exothermicity of $\mathrm{CO}$ is higher than that of hydrogen. Although the moderation of the surface temperatures by $\mathrm{CO}$ addition may be an advantage for steady reactor operation, it nonetheless impacts the catalytic ignition characteristics (see discussion in the next section). At steady operation and under the high surface temperatures of Figures 13 and 14, the catalytic and gas-phase pathways of $\mathrm{CO}$ and $\mathrm{H}_{2}$ are decoupled from each other as discussed in the foregoing section. Therefore, the practical measures to moderate the surface temperatures are the same as those discussed in the hydrogen combustion section,

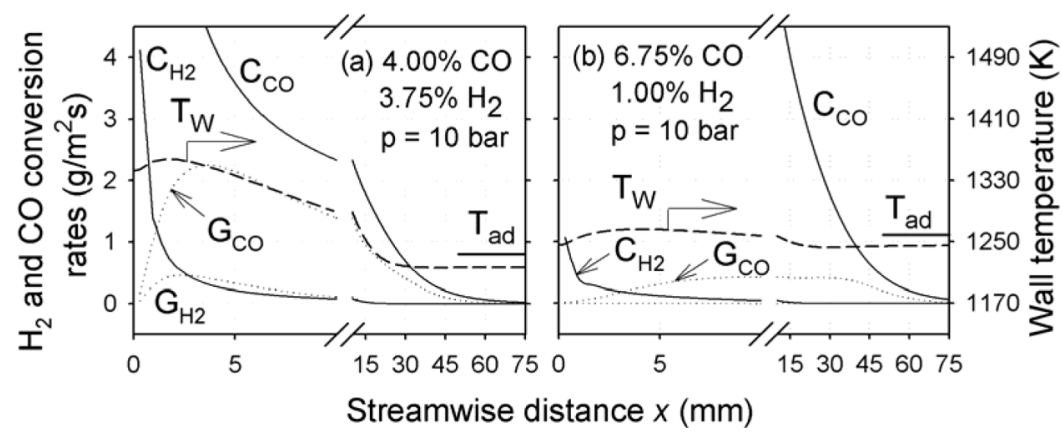

Figure 14 Computed axial profiles of catalytic ( $C$, solid lines) and gas-phase $(G$, dotted lines) conversion rates of $\mathrm{H}_{2}$ and $\mathrm{CO}$, and wall temperature ( $T_{W}$, dashed lines). $\mathrm{H}_{2} / \mathrm{CO} /$ air mixtures with two different $\mathrm{H}_{2} / \mathrm{CO}$ compositions, $p=10 \mathrm{bar}, U_{\mathrm{IN}}=2 \mathrm{~m} / \mathrm{s}$, and $T_{\mathrm{IN}}=600 \mathrm{~K}$. The horizontal lines marked $T_{\mathrm{ad}}$ provide the adiabatic equilibrium temperature. For clarity, the first $10 \mathrm{~mm}$ are expanded. The $y$-axis scale is chosen so as to facilitate comparisons of both $\mathrm{H}_{2}$ and $\mathrm{CO}$ conversions: at $x \sim 0, C_{\mathrm{CO}}$ reaches $\sim 34 \mathrm{~g} / \mathrm{m}^{2} \mathrm{~s}$ in (a) and $\sim 55 \mathrm{~g} / \mathrm{m}^{2} \mathrm{~s}$ in (b). 
i.e., increasing the channel radius or applying passive cooling with alternate-coated channels.

\section{Catalytic Ignition}

The ignition characteristics of $\mathrm{CO}$ and $\mathrm{H}_{2}$ mixtures are explored in this section with transient simulations. Three different syngas/air mixtures are considered with a total volumetric $\mathrm{H}_{2}$ and $\mathrm{CO}$ content of $7.75 \%$; therein, hydrogen comprises $0.5 \%$, $1.0 \%$ and $3.75 \%$ vol. of the mixture. Computations have also been carried out with $\mathrm{H}_{2}{ }^{*} / \mathrm{CO}$ mixtures, whereby the $\mathrm{H}_{2}$ content of the syngas was replaced by a chemically inert fictitious species $\mathrm{H}_{2}{ }^{*}$ that had the same thermodynamic and transport properties as $\mathrm{H}_{2}$ but did not participate in any reaction. For each of the three $\mathrm{H}_{2}$ (and $\mathrm{H}_{2}{ }^{*}$ ) compositions, inlet temperatures of 620,650 , and $700 \mathrm{~K}$ were investigated at pressures of 1 and 10 bar.

For $T_{\mathrm{IN}}=650 \mathrm{~K}$ ignition was achieved in all cases (with addition of $\mathrm{H}_{2}$ or $\mathrm{H}_{2}{ }^{*}$ ) and pressures, while For $T_{\mathrm{IN}}=620 \mathrm{~K}$ ignition was not possible again for all cases. Thus, a first conclusion is that the addition of even sizeable amounts of hydrogen cannot lower the ignition temperatures of syngas to the corresponding values of pure hydrogen $(360-380 \mathrm{~K})$. Alternately, the addition CO clearly inhibits the catalytic ignition of hydrogen. This inhibition has its origin in the transition temperature below which the effect of $\mathrm{CO}$ blocking commences (ca. $700 \mathrm{~K}$ as discussed in the foregoing sections). The $\mathrm{H}_{2} / \mathrm{CO}$ mixtures, therefore, exhibit catalytic ignition characteristics similar to those of the pure $\mathrm{CO}$, irrespective of the amount of added hydrogen.

In recent steady simulations over a platinum stagnation surface using a surface reaction mechanism slightly modified compared to that of Table A1, Chao et al. (2003) reported that the addition of $2.7 \%$ vol. $\mathrm{H}_{2}$ in $3.6 \%$ vol. $\mathrm{CO}$ marginally reduced the required for ignition mixture preheat by 14 to $19 \mathrm{~K}$, depending on the strain rate. Such potentially small preheat temperature improvements cannot be investigated using as platform the computationally expensive 2D transient channel code - considering also the rapidly increasing integration time requirements at mixture preheats close to light-off. For this reason, catalytic ignition delay times have initially been computed using the SENKIN program of CHEMKIN (Lutz et al., 1996) that has been augmented with heterogeneous reactions. This approach also allows for the decoupling of pure kinetic effects from reactor parameters (heat loss mechanisms, properties of solid, etc.) It is further noted that the computed catalytic ignition delays were unaffected by the inclusion of gaseous pathway. The results are summarized in Figure 15 for $T_{\mathrm{IN}}=700 \mathrm{~K}, p=10 \mathrm{bar}, 0.5 \%$ vol. $\mathrm{H}_{2}\left(\right.$ or $\left.\mathrm{H}_{2}{ }^{*}\right)$ and $7.25 \%$ vol. CO. The catalytic ignition delay is longer in the $\mathrm{CO} / \mathrm{H}_{2}$ compared to the $\mathrm{CO} / \mathrm{H}_{2}{ }^{*}$ mixture (Fig. 15a).

Further computations have shown that this result is irrespective of hydrogen content or pressure, clearly demonstrating that hydrogen inhibits the catalytic ignition of $\mathrm{CO}$. The underlying reason is that the surface hydrogen, $\mathrm{H}(\mathrm{s})$, reduces the $\mathrm{O}(\mathrm{s})$ coverage, which is in turn needed for the $\mathrm{CO}(\mathrm{s})$ oxidation (see Fig. 15b, $15 \mathrm{c})$ ). The $\mathrm{O}(\mathrm{s})$ profile of Figure $15 \mathrm{~b}$ actually points to a two-stage ignition, first of $\mathrm{H}_{2}$ at $t \approx 5.5 \mathrm{~s}$ and then of $\mathrm{CO}$ at $t \approx 12 \mathrm{~s}$. The former is a pseudo-ignition since $\mathrm{H}_{2}$ conversion starts already at $t=0$ (Fig. 15a); however, the drastic drop of $\mathrm{H}(\mathrm{s})$ and rise of $\mathrm{O}(\mathrm{s})$ at $t \approx 5.5 \mathrm{~s}$, which is induced by the decreasing $\mathrm{H}_{2}$ and increasing 

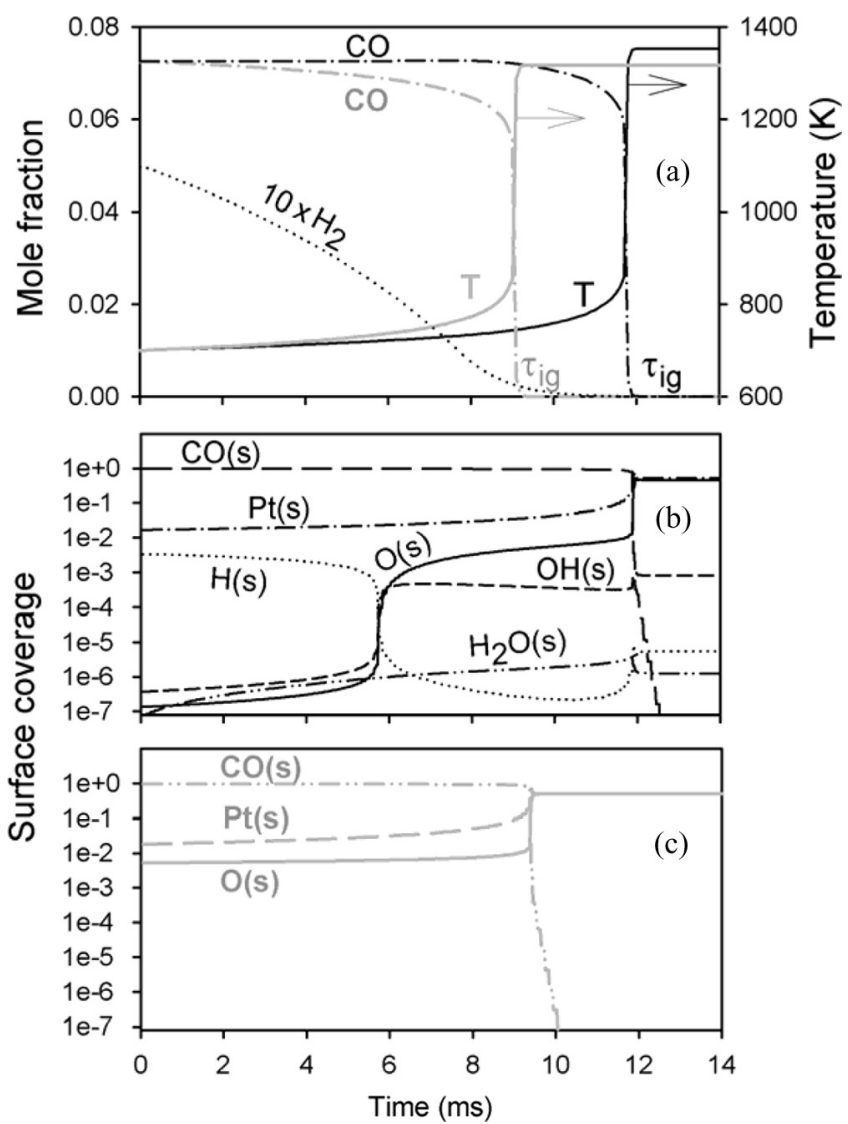

Figure 15 Computed time histories in a batch reactor with $p=10 \mathrm{bar}, T_{\mathrm{IN}}=700 \mathrm{~K}$, surface to volume ratio of $33.3 \mathrm{~cm}^{-1}$, and composition $0.5 \% \mathrm{H}_{2}$ and $7.25 \% \mathrm{CO}$ vol. in air; (a) major gas phase species and temperature (black lines: $\mathrm{H}_{2}$, gray lines: chemically inert $\mathrm{H}_{2}{ }^{*}$ ), (b) major surface species coverage for $\mathrm{H}_{2}$ addition, (c) major surface species coverage for $\mathrm{H}_{2}{ }^{*}$ addition. In (a), the ignition delay times are indicated by $\tau_{\text {ig }}$.

temperature levels, is reminiscent of a typical hydrogen ignition (Deutschmann et al., 1996).

Although the aforementioned inhibition may appear contentious, it is nonetheless modest: as stated before, it can potentially lead to a maximum preheat temperature increase of $30 \mathrm{~K}$ (from 620 to $650 \mathrm{~K}$ ). In conclusion, the addition of $\mathrm{H}_{2}$ in $\mathrm{CO}$ does not have a clear benefit for the catalytic ignition of CO: depending on the employed catalytic reaction mechanism, it either aids the ignition of $\mathrm{CO}$ by lowering the preheat requirements by a meager $14-19 \mathrm{~K}$ or it inhibits $\mathrm{CO}$ ignition by increasing the preheat by a few tens of degrees. In either case, this difference is small for practical systems and does not impact seriously the reactor design. Nonetheless, detailed experiments are needed to resolve this apparent controversy.

Typical transient computations in the channel of Figure 1 are shown in Figure 16 for syngas with $0.5 \%$ vol. hydrogen and inlet temperature of $700 \mathrm{~K}$. Axial profiles are provided (black lines: $\mathrm{H}_{2}$, gray lines $\mathrm{H}_{2}{ }^{*}$ ) for the wall temperatures, the 


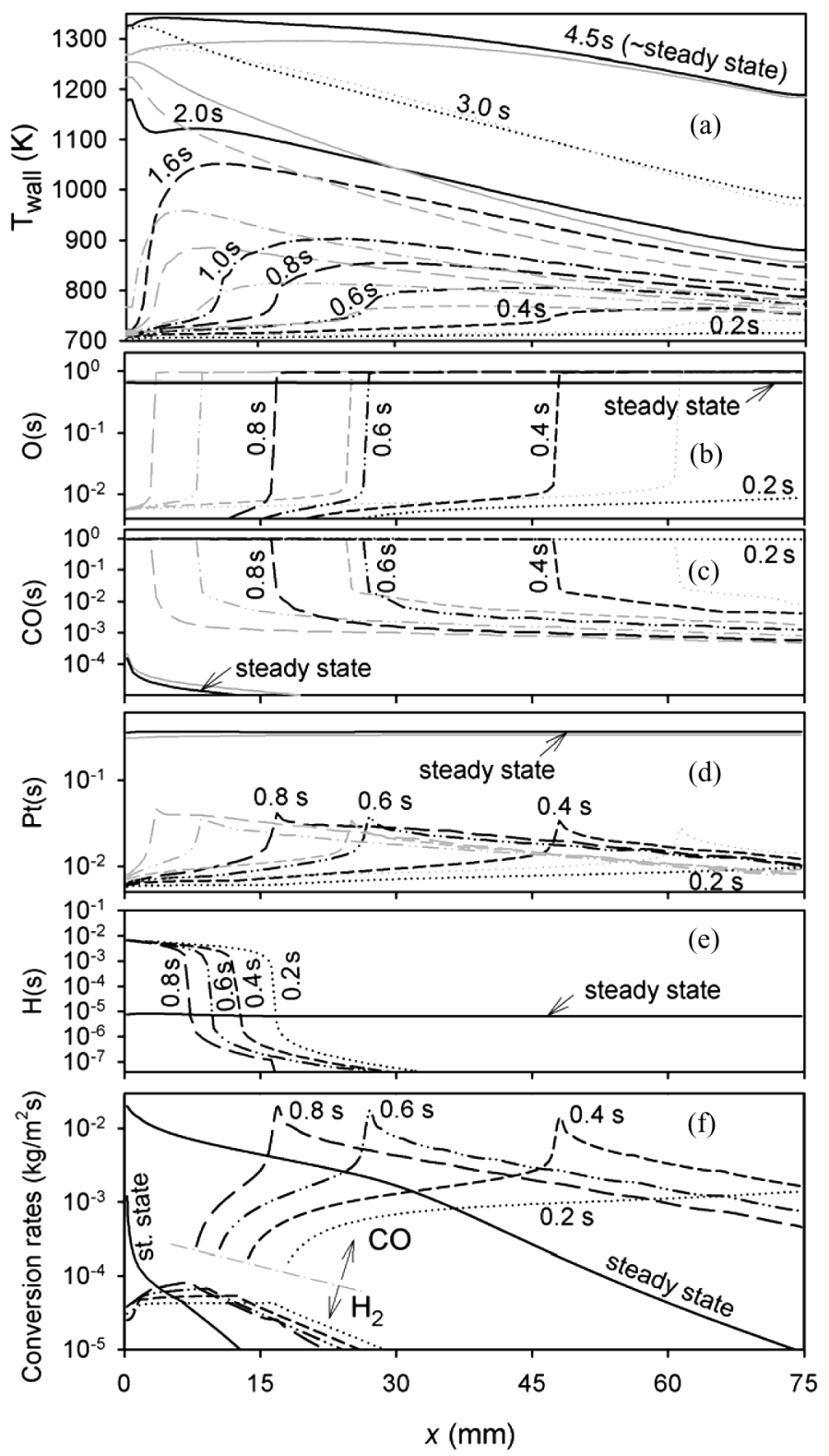

Figure 16 Computed axial profiles at different times during light-off of a syngas/air mixture in the channel of Figure $1\left(0.5 \% \mathrm{H}_{2}\right.$ and $7.25 \% \mathrm{CO}$ vol., $\left.p=10 \mathrm{bar}, U_{\mathrm{IN}}=2 \mathrm{~m} / \mathrm{s}, T_{\mathrm{IN}}=700 \mathrm{~K}\right)$ : (a) wall temperatures, (b)-(e) major surface species coverage, and (f) $\mathrm{CO}$ and $\mathrm{H}_{2}$ conversion rates. In (b) to (f) results are presented at the early phases (up to $0.8 \mathrm{~s}$ ) and at steady state. The black lines refer to $\mathrm{H}_{2}$ content and the gray lines in (a) to (d) to chemically inert $\mathrm{H}_{2}{ }^{*}$. 
major surface species coverage, and the catalytic conversion rates at selected time intervals; the coverage and conversion plots are shown at early times (up to $0.8 \mathrm{~s}$ ) and also during steady state. As seen in Figure 16a, the wall heat-up commences at the rear of the channel and then propagates upstream; at the same time, the main surface coverage shifts from $\mathrm{CO}(\mathrm{s})$ to $\mathrm{O}(\mathrm{s})$ (Figs. 16b, 16c). At times $t<1.0 \mathrm{~s}$, the propagation of the front is faster in the $\mathrm{H}_{2}{ }^{*}$ than in the $\mathrm{H}_{2}$ dilution case (Fig. 16a); at those times there is minimal $\mathrm{H}_{2}$ consumption and only $\mathrm{CO}$ is converted appreciably (Fig. 16f).

For $t>2 \mathrm{~s}$, however, $\mathrm{H}_{2}$ catalytic ignition is accomplished and the heat-up of the solid is faster in the $\mathrm{H}_{2}$ dilution case due to the added heat generated from the hydrogen conversion. The total time required to reach steady state is roughly the same in both cases $(\sim 4.5 \mathrm{~s}$, see Fig. 16a). The inhibition due to hydrogen addition at the initial stages of Fig. 16a follows much the same path described in Figure 15: $\mathrm{H}(\mathrm{s})$ is formed at early times at the front section of the reactor and upon hydrogen ignition it drops to the low steady state levels (Fig. 16e).

For $T_{\mathrm{IN}}=650 \mathrm{~K}, 3.75 \% \mathrm{H}_{2}$ and $4.0 \% \mathrm{CO}$ vol. content, $p=10 \mathrm{bar}$ and $U_{\text {IN }}=2 \mathrm{~m} / \mathrm{s}$, the light-off times increase. Ignition is still attained for both $\mathrm{H}_{2}$ and $\mathrm{H}_{2}{ }^{*}$ dilutions and the steady states are practically reached at 13 and $9 \mathrm{~s}$, respectively (see Fig. 17). Again, during the initial phase of the light-off event, the inhibition of the added hydrogen is strong. Following hydrogen catalytic ignition, the resulting exothermicity of the $\mathrm{H}_{2}$ dilution accelerates considerably the heat-up of the solid; nonetheless, the overall time to reach steady state is longer in the $\mathrm{H}_{2}$ case. It is emphasized that in practical systems the relevant parameter that determines the minimum preheat requirements for ignition is predominately the initial phase of light-off wherein hydrogen plays an inhibiting role.

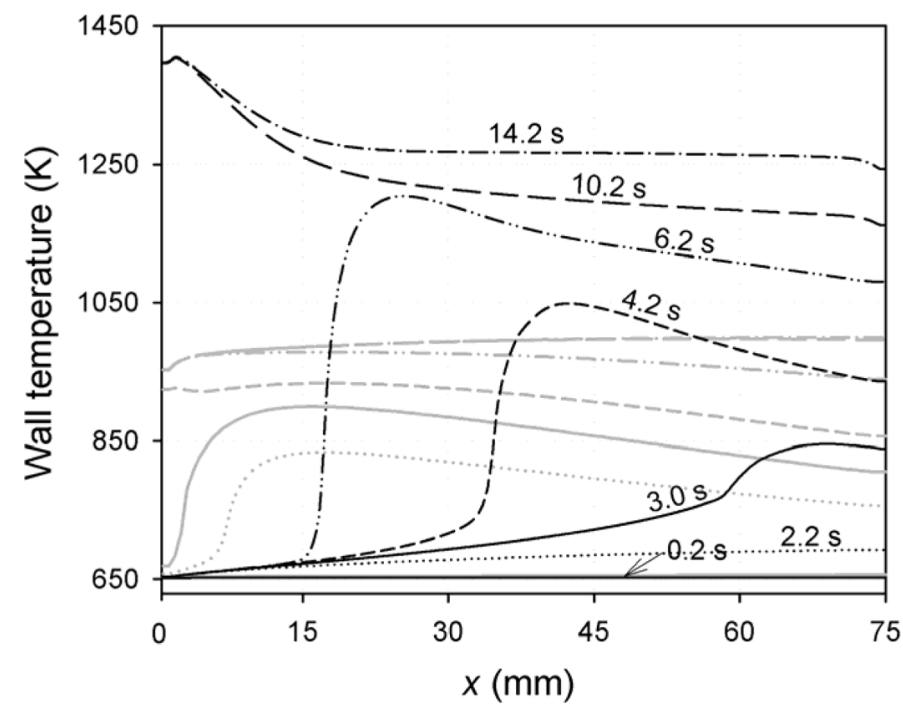

Figure 17 Computed axial profiles at different times of the wall temperature during light-off of a syngas/air mixture in the channel of Figure 1 for $3.75 \% \mathrm{H}_{2}$ and $4.0 \% \mathrm{CO}$ vol., $p=10 \mathrm{bar}, U_{\mathrm{IN}}=2 \mathrm{~m} / \mathrm{s}, T_{\mathrm{IN}}=650 \mathrm{~K}$ (black lines). The gray lines refer to the same case when $\mathrm{H}_{2}$ is substituted by chemically inert $\mathrm{H}_{2}{ }^{*}$. 
Finally, the transient model of this section is of interest not only for the description of catalytic ignition but also for the investigation of kinetically driven dynamic oscillatory phenomena (Imbihl and Ertl, 1995) that may appear during syngas catalytic combustion. In the catalytic oxidation of both hydrogen and carbon monoxide over noble metals, oscillatory behavior has been reported (Yamamoto et al., 1995; Yakhnin and Menzinger, 2002; Carlsson et al., 2006). It is plausible that for certain operating regimes of power generation systems such phenomena may also appear. This behavior is undesirable for practical devices and may require specific startup procedures and well-defined operational envelopes in order to circumvent unstable combustion modes.

\section{CONCLUSIONS}

The catalytic combustion of syngas/air mixtures over Pt has been investigated numerically in a channel-flow configuration using $2 \mathrm{D}$ steady and transient elliptic codes with detailed hetero-/homogeneous chemistry and transport. Simulations were carried out for syngas compositions with varying $\mathrm{H}_{2}$ and COcontents (including pure $\mathrm{H}_{2}$ and $\mathrm{CO}$ fuels), pressures of 1 to $15 \mathrm{bar}$, and linear velocities relevant to power generation applications. The following are the key conclusions of this study.

(1) Despite the large geometrical confinements of typical honeycomb catalytic reactors, the homogeneous combustion of both $\mathrm{H}_{2}$ and $\mathrm{CO}$ cannot be neglected, particularly at elevated pressures and temperatures. Therefore, the catalytic combustion of syngas at practical pressures should be viewed as a combined hetero-/homogeneous process.

(2) Above a transition temperature of about $700 \mathrm{~K}$, which is roughly independent of pressure and particular syngas composition, there is no chemistry coupling between the heterogeneous pathways of $\mathrm{CO}$ and $\mathrm{H}_{2}$, the reason being that sufficient free $\mathrm{Pt}$ sites are available to accommodate the oxidation of both fuel components. Moreover, at sufficiently high (but still acceptable for catalytic operation) temperatures $T>1150 \mathrm{~K}$ and for pressures $p>10 \mathrm{bar}$, the gas phase reaction pathway of both $\mathrm{CO}$ and $\mathrm{H}_{2}$ is important, with the former crucially dependent on the radical pool provided by the latter. At those temperatures, the chemical coupling between the heterogeneous pathway of one fuel component and the homogeneous pathway of the other is minimal.

(3) Even though the gas-phase ignition characteristics of hydrogen are intricately dependent on temperature and pressure, for the operational maps of catalytic combustion systems (which include not only pressure and temperature but also the competition of the gaseous and catalytic pathways for the consumption of hydrogen) the relevant behavior is that the gaseous reactivity of hydrogen increases with rising pressure, at least for pressures up to 10 bar. Moreover, the gaseous reactivity of $\mathrm{CO}$ is accelerated with increasing pressure.

(4) In syngas catalytic combustion the diffusional imbalance of hydrogen can lead (depending on the hydrogen content) to excessively large superadiabatic surface temperatures, which may endanger the catalyst integrity and cause reactor meltdown. The diffusional imbalance of hydrogen also confines the gaseous combustion of this species close to hot catalytic wall. It is shown that, contrary 
to hydrocarbon fuel catalytic combustion, the presence of gaseous combustion moderates the superadiabatic wall temperatures by shielding the catalyst from the hydrogen-rich channel core.

(5) Based on the previous conclusion, strategies for reactor thermal management are presented, which include reactors with smaller geometrical confinements (larger channel radii) so as to promote homogeneous combustion of hydrogen at the expense of catalytic combustion. Other appropriate thermal management strategies include combustion in alternately-coated monolithic reactors; however, this approach requires the use of a post-catalyst gaseous combustion zone in order to complete the conversion of the fuel.

(6) Below the transition temperature of $\sim 700 \mathrm{~K}$ the chemical coupling between the $\mathrm{CO}$ and $\mathrm{H}_{2}$ catalytic pathways is strong; the catalyst is predominantly covered by $\mathrm{CO}$ that, in turn, inhibits the catalytic conversion of both fuel components.

(7) The catalytic ignition temperatures of $\mathrm{H}_{2} /$ air and $\mathrm{CO} /$ air fuels are $360-380 \mathrm{~K}$ and $650-700 \mathrm{~K}$, respectively, over a range of reactor and flow parameters relevant for power generation applications. While the addition of $\mathrm{CO}$ in $\mathrm{H}_{2}$ clearly inhibits the catalytic ignition of the latter, there is no clear improvement in the ignition characteristics of $\mathrm{CO}$ by adding $\mathrm{H}_{2}$ due to the dominant $\mathrm{CO}$ surface blocking at temperatures below $700 \mathrm{~K}$. Depending on the employed catalytic chemical reaction scheme, the catalytic ignition temperatures for $\mathrm{CO} / \mathrm{H}_{2} /$ air mixtures can either drop (compared to those of $\mathrm{CO} /$ air mixtures) by a marginal $14-19 \mathrm{~K}$ or increase by a few tens of degrees. On the other hand, in syngas combustion the nearly neutral transport properties of $\mathrm{CO}$ moderate the superadiabatic surface temperatures, thus simplifying the reactor design and its thermal management.

\section{REFERENCES}

Allgeier, T., Klenk, M., Landenfeld, T., Conte, E., Boulouchos, K., and Czerwinski, J. (2004) Advanced emission and fuel economy concept using combined injection of gasoline and hydrogen in SI-engines. SAE Paper 2004-2001-1270.

Appel, C., Mantzaras, J., Schaeren, R., Bombach, R., Inauen, A., Kaeppeli, B., Hemmerling, B., and Stampanoni, A. (2002) An experimental and numerical investigation of homogeneous ignition in catalytically stabilized combustion of hydrogen/air mixtures over platinum. Combust. Flame, 128, 340-368.

Appel, C., Mantzaras, J., Schaeren, R., Bombach, R., Inauen, A., Tylli, N., Wolf, M., Griffin, T., Winkler, D., and Carroni, R. (2005a) Partial catalytic oxidation of methane to synthesis gas over rhodium: In situ Raman experiments and detailed simulations. Proc. Combust. Instit., 30, 2509-2517.

Appel, C., Mantzaras, J., Schaeren, R., Bombach, R., and Inauen, A. (2005b) Turbulent catalytically stabilized combustion of hydrogen/air mixtures in entry channel flows. Combust. Flame, 140, 70-92.

Beebe, K.W., Cairns, K.D., Pareek, V.K., Nickolas, S.G., Schlatter, J.C., and Tsuchiya, T. (2000) Development of catalytic combustion technology for single-digit emissions from industrial gas turbines. Catal. Today, 59, 95-115.

Boehman, A.L. and Le Corre, O. (2008) Combustion of syngas in internal combustion engines. Combust. Sci. Technol., (in press) 
Bui, P.A., Vlachos, D.G., and Westmoreland, P.R. (1996) Homogeneous ignition of hydrogen/air mixtures over platinum. Proc. Combust. Instit., 26, 1763-1770.

Carlsson, P.A., Zhdanov, V., and Skoglundh, M. (2006) Self-sustained kinetic oscillations in CO oxidation over silica-supported Pt. Phys. Chem. Chem. Phys., 8, 2703-2706.

Carroni, R., Schmidt, V., and Griffin, T. (2002) Catalytic combustion for power generation. Catal. Today, 75, 287-295.

Carroni, R., Griffin, T., Mantzaras, J., and Reinke, M. (2003) High-pressure experiments and modeling of methane/air catalytic combustion for power generation applications. Catal. Today, 83, 157-170.

Chao, Y.-C., Chen, G.-B., and Hsu, H.-W. (2003) Catalytic ignition of multifuels on platinum: Effect of strain rate. Catal. Today, 83, 97-113.

Chaos, M. and Dryer, F.L. (2008) Syngas combustion kinetics and applications. Combust. Sci. Technol., (in press).

Coltrin, M.E., Kee, R.J., and Rupley, F.M. (1996) Surface Chemkin: A Fortran package for analyzing heterogeneous chemical kinetics at the solid surface-gas phase interface, Sandia National Laboratories, Report No. SAND90-8003C.

Deutschmann, O., Schmidt, R., Behrendt, F., and Warnatz, J. (1996) Numerical modeling of catalytic ignition. Proc. Combust. Instit., 26, 1747-1754.

Deutschmann, O., Maier, L.I., Riedel, U., Stroemman, A.H., and Dibble, R.W. (2000) Hydrogen assisted catalytic combustion of methane on platinum. Catal. Today, 59, 141-150.

Dogwiler, U., Mantzaras, J., Benz, P., Kaeppeli, B., Bombach, R., and Arnold, A. (1998) Homogeneous ignition of methane/air mixtures over platinum: Comparison of measurements and detailed numerical predictions. Proc. Combust. Instit., 27, 2275-2282.

Dogwiler, U., Benz, P., and Mantzaras, J. (1999) Two-dimensional modelling for catalytically stabilized combustion of a lean methane-air mixture with elementary homogeneous and heterogeneous chemical reactions. Combust. Flame, 116, 243-258.

Eriksson, S., Wolf, M., Schneider, A., Mantzaras, J., Raimondi, F., Boutonnet, M., and Järas, S. (2006) Fuel rich catalytic combustion of methane in zero emissions power generation processes. Catal. Today, 117, 447-453.

Etemad, S., Smith, L.L., and Burns, K. (2004) System study of rich catalytic/lean burn (RCL) catalytic combustion for natural gas and coal-derived syngas combustion turbines, DOE final report DE-FG26-02NT41521, Precision Combustion.

Glassman, I. (1996) Combustion, Academic Press, San Diego, p. 75.

Griffin, T., Winkler, D., Wolf, M., Appel, C., and Mantzaras, J. (2004) Staged catalytic combustion method for the advanced zero emissions gas turbine power plant. Proceedings ASME Turbo Expo, paper GT2004-54101, Vienna, Austria, June 14-17.

Griffin, T., Sundkvist, S.G., Asen, K.I., and Bruun, T. (2005) Advanced zero emissions gas turbine power plant. J. Eng. Gas Turbines Power, 127, 81-85.

Groppi, G., Belloli, A., Tronconi, E., and Forzatti, P. (1996) Catalytic combustion of CO-H 2 mixtures on manganese-substituted hexaaluminates. Catal. Today, 29, 403-407.

Imbihl, R. and Ertl, G. (1995) Oscillatory kinetics in heterogeneous catalysis. Chem. Reviews, 95, 697-733.

Johansson, E.M., Danielsson, K.M.J., Ersson, A.G., and Järas, S.G. (2002) Development of hexaaluminate catalysts for combustion of gasified biomass in gas turbines. J. Eng. Gas Turbines ans Power, 124, 235-238.

Karagiannidis, S., Mantzaras, J., Jackson, G., and Boulouchos, K. (2007) Hetero-/ homogeneous combustion and stability maps in methane-fueled microreactors. Proc. Combust. Instit., 31, 3309-3317.

Karim, H., Lyle, K., Etemad, S., Smith, L., Pfefferle, W.C., Dutta, P., and Smith, K. (2002) Advanced catalytic pilot for low $\mathrm{NO}_{\mathrm{x}}$ industrial gas turbines. Proceedings ASME Turbo Expo, paper GT2002-30083, Amsterdam, Holland, June 3-6. 
Kee, R.J., Dixon-Lewis, G., Warnatz, J., Coltrin, M.E., and Miller, J.A. (1996a) A Fortran computer code package for the evaluation of gas-phase multicomponent transport properties, Sandia National Laboratories, Report No. SAND86-8246.

Kee, R.J., Rupley, F.M., and Miller, J.A. (1996b) Chemkin II: A Fortran chemical kinetics package for the analysis of gas-phase chemical kinetics, Sandia National Laboratories, Report No. SAND89-8009B.

Law, C.K. and Sivashinsky, G.I. (1982) Catalytic extension of extinction limits of stretched premixed flames. Combust. Sci. Technol., 29, 277-286

Li, J., Zhao, Z., Kazakov, A., and Dryer, F.L. (2003) An updated comprehensive kinetic model for $\mathrm{H}_{2}$ combustion. Fall Technical Meeting of the Eastern States Section of the Combustion Institute, Pennsylvania State University, October 26-29.

Lutz, A.E., Kee, R.J., and Miller, J.A. (1996) SENKIN: A Fortran program for predicting homogeneous gas phase chemical kinetics with sensitivity analysis, Sandia National Laboratories, Report No. SAND87-8248.

Mantzaras, J. and Benz, P. (1999). An asymptotic and numerical investigation of homogeneous ignition in catalytically stabilized channel flow combustion. Combust. Flame, 119, 455-472.

Mantzaras, J., Appel, C., and Benz, P. (2000) Catalytic combustion of methane/air mixtures over platinum: Homogeneous ignition distances in channel flow configurations. Proc. Combust. Instit., 28, 1349-1357.

Mantzaras, J. (2006a) Understanding and modeling of thermofluidic processes in catalytic combustion. Catal. Today, 117, 394-406.

Mantzaras, J. (2006b) Interplay of transport and hetero-/homogeneous chemistry. In Jiang, S.Z. (Ed.) Focus on Combustion Research, Nova Science Publishers, New York, Chap. 8, pp. 241-314.

Mantzaras, J., Bombach, R., and Schaeren, R. (2008) Homogeneous ignition in catalytic combustion of hydrogen/air mixtures over platinum at pressures of up to $10 \mathrm{bar}$, submitted.

Neathery, J., Gray, D., Challman, D., and Derbyshire, F. (1999) The pioneer plant concept: Co-production of electricity and added-value products from coal. Fuel, 78, 815-823.

ONSE (1999) (Onsite Energy Corporation) Cost analysis of $\mathrm{NO}_{\mathrm{x}}$ control alternatives for stationary gas turbines.

Pfefferle, W.C. and Pfefferle, L.D. (1986) Catalytically stabilized combustion. Prog. Energy Combust. Sci., 12, 25-41.

Pocoroba, E., Johansson, E.M., and Järas, S.G. (2000) Ageing of palladium, platinum and manganese-based combustion catalysts for biogas applications. Catal. Today, 59, 179-189.

Reinke, M., Mantzaras, J., Schaeren, R., Bombach, R., Kreutner, W., and Inauen, A. (2002) Homogeneous ignition in high-pressure combustion of methane/air over platinum: Comparison of measurements and detailed numerical predictions. Proc. Combust. Instit., 29, 1021-1029.

Reinke, M., Mantzaras, J., Schaeren, R., Bombach, R., Inauen, A., and Schenker, S. (2004) High-pressure catalytic combustion of methane over platinum: In situ experiments and detailed numerical predictions. Combust. Flame, 136, 217-240.

Reinke, M., Mantzaras, J., Bombach, R., Schenker, S., and Inauen, A. (2005) Gas phase chemistry in catalytic combustion of methane/air mixtures over platinum at pressures of 1 bar to 16 bar. Combust. Flame, 141, 448-468.

Reinke, M., Mantzaras, J., Bombach, R., Schenker, S., Tylli, N., and Boulouchos, K. (2007) Effects of $\mathrm{H}_{2} \mathrm{O}$ and $\mathrm{CO}_{2}$ dilution on the catalytic and gas-phase combustion of methane over platinum at elevated pressures. Combust. Sci. Technol., 179, 553-600.

Schlegel, A., Benz, P., Griffin, T., Weisenstein, W., and Bockhorn, H. (1996) Catalytic stabilization of lean premixed combustion: Method for improving $\mathrm{NO}_{\mathrm{x}}$ emissions. Combust. Flame, 105, 332-340. 
Schneider, A., Mantzaras, J., and Jansohn, P. (2006) Experimental and numerical investigation of the catalytic partial oxidation of $\mathrm{CH}_{4} / \mathrm{O}_{2}$ mixtures diluted with $\mathrm{H}_{2} \mathrm{O}$ and $\mathrm{CO}_{2}$ in a short contact time reactor. Chem. Eng. Sci., 61, 4634- 4646.

Schneider, A., Mantzaras, J., Bombach, R., Schenker, S., Tylli, N., and Jansohn, P. (2007). Laser induced fluorescence of formaldehyde and Raman measurements of major species during partial catalytic oxidation of methane with large $\mathrm{H}_{2} \mathrm{O}$ and $\mathrm{CO}_{2}$ dilution at pressures up to 10 bar. Proc. Combust. Instit., 31, 1973-1981.

Schneider, A., Mantzaras, J., and Eriksson, S. (2008) Ignition and extinction in catalytic partial oxidation of methane-oxygen mixtures with large $\mathrm{H}_{2} \mathrm{O}$ and $\mathrm{CO}_{2}$ dilution, Combust. Sci. Technol., 180, 89-126.

Schwiedernoch, R., Tischer, S., Correa, C., and Deutschmann, O. (2003) Experimental and numerical study on the transient behavior of partial oxidation of methane in a catalytic monolith. Chem. Eng. Sci., 58, 633-642.

Siegel, R. and Howell, J.R. (1981) Thermal Radiation Heat Transfer. Hemisphere, New York, p. 271.

Sinha, N., Bruno, C., and Bracco, F.V. (1985) Two-dimensional, transient catalytic combustion of CO-air on platinum. Physicochem. Hydrod., 6, 373-391.

Walton, S.M., He, X., Zigler, B.T., and Wooldridge, M.S. (2007) An experimental investigation of the ignition properties of hydrogen and carbon monoxide mixtures for syngas turbine applications. Proc. Combust. Instit., 31,3147-3154.

Warnatz, J. (2005) Personal communication.

Warnatz, J., Allendorf, M.D., Kee, R.J., and Coltrin, M.E. (1994) A model of elementary chemistry and fluid mechanics in the combustion of hydrogen on platinum surfaces. Combust. Flame, 96, 393-406.

Warnatz, J., Dibble, R.W., and Maas, U. (1996) Combustion, Physical and Chemical Fundamentals, Modeling and Simulation, Springer-Verlag, New York.

Wender, I. (1996) Reactions of synthesis gas. Fuel Proc. Technol., 48, 189-297.

Yakhnin, V. and Menzinger, M. (2002) Stationary and travelling hot spots in the catalytic combustion of hydrogen in monoliths. Chem. Eng. Sci., 57, 4559-4567.

Yamamoto, S.Y., Surko, C.M., Maple, M.B., and Pina, R.K. (1995) Spatio-temporal dynamics of oscillatory heterogeneous catalysis: $\mathrm{CO}$ oxidation on platinum. J. Chem. Phys., 102, 8614-8625.

Zwinkels, M.F.M., Järas, S.G., Menon, P.G., and Griffin, T.A. (1993) Catalytic materials for high-temperature combustion. Catal. Rev. Sci. Eng., 35, 319-358. 


\section{APPENDIX A}

\section{Catalytic and Gas-Phase Chemical Reaction Mechanisms}

Table A1 Catalytic reaction scheme for $\mathrm{H}_{2} / \mathrm{CO}$ oxidation on $\mathrm{Pt}^{(a)}$

\begin{tabular}{|c|c|c|c|}
\hline & $A(\gamma)$ & $b$ & $E$ \\
\hline \multicolumn{4}{|l|}{ Adsorption reactions } \\
\hline $\mathrm{S} 1 . \mathrm{O}_{2}+2 \mathrm{Pt}(\mathrm{s}) \rightarrow 2 \mathrm{O}(\mathrm{s})$ & 0.023 & 0.0 & 0.0 \\
\hline $\mathrm{S} 2 . \mathrm{O}_{2}+2 \mathrm{Pt}(\mathrm{s}) \rightarrow 2 \mathrm{O}(\mathrm{s})$ & $1.8 \times 10^{21}$ & -0.5 & 0.0 \\
\hline $\mathrm{S} 3 . \mathrm{H}_{2}+2 \mathrm{Pt}(\mathrm{s}) \rightarrow 2 \mathrm{H}(\mathrm{s})$ & $4.5 \times 10^{10}$ & 0.5 & 0.0 \\
\hline $\mathrm{S} 4 . \mathrm{H}+\mathrm{Pt}(\mathrm{s}) \rightarrow \mathrm{H}(\mathrm{s})$ & 1.0 & 0.0 & 0.0 \\
\hline $\mathrm{S} 5 . \mathrm{O}+\mathrm{Pt}(\mathrm{s}) \rightarrow \mathrm{O}(\mathrm{s})$ & 1.0 & 0.0 & 0.0 \\
\hline S6. $\mathrm{H}_{2} \mathrm{O}+\mathrm{Pt}(\mathrm{s}) \rightarrow \mathrm{H}_{2} \mathrm{O}(\mathrm{s})$ & 0.75 & 0.0 & 0.0 \\
\hline $\mathrm{S} 7 . \mathrm{OH}+\mathrm{Pt}(\mathrm{s}) \rightarrow \mathrm{OH}(\mathrm{s})$ & 1.0 & 0.0 & 0.0 \\
\hline $\mathrm{S} 8 . \mathrm{CO}+\mathrm{Pt}(\mathrm{s}) \rightarrow \mathrm{CO}(\mathrm{s})$ & $1.6 \times 10^{20}$ & 0.5 & 0.0 \\
\hline \multicolumn{4}{|l|}{ Surface reactions } \\
\hline $\mathrm{S} 9 . \mathrm{H}(\mathrm{s})+\mathrm{O}(\mathrm{s})=\mathrm{OH}(\mathrm{s})+\mathrm{Pt}(\mathrm{s})$ & $3.7 \times 10^{21}$ & 0.0 & 11.5 \\
\hline $\mathrm{S} 10 . \mathrm{H}(\mathrm{s})+\mathrm{OH}(\mathrm{s})=\mathrm{H}_{2} \mathrm{O}(\mathrm{s})+\mathrm{Pt}(\mathrm{s})$ & $3.7 \times 10^{21}$ & 0.0 & 17.4 \\
\hline $\mathrm{S} 11 . \mathrm{OH}(\mathrm{s})+\mathrm{OH}(\mathrm{s})=\mathrm{H}_{2} \mathrm{O}(\mathrm{s})+\mathrm{O}(\mathrm{s})$ & $3.7 \times 10^{21}$ & 0.0 & 48.2 \\
\hline $\mathrm{S} 12 . \mathrm{C}(\mathrm{s})+\mathrm{O}(\mathrm{s}) \rightarrow \mathrm{CO}(\mathrm{s})+\mathrm{Pt}(\mathrm{s})$ & $3.7 \times 10^{21}$ & 0.0 & 62.8 \\
\hline $\mathrm{S} 13 . \mathrm{CO}(\mathrm{s})+\mathrm{Pt}(\mathrm{s}) \rightarrow \mathrm{C}(\mathrm{s})+\mathrm{O}(\mathrm{s})$ & $1.0 \times 10^{18}$ & 0.0 & 184.0 \\
\hline $\mathrm{S} 14 . \mathrm{CO}(\mathrm{s})+\mathrm{O}(\mathrm{s}) \rightarrow \mathrm{CO}_{2}(\mathrm{~s})+\mathrm{Pt}(\mathrm{s})$ & $3.7 \times 10^{21}$ & 0.0 & 105.0 \\
\hline \multicolumn{4}{|l|}{ Desorption reactions } \\
\hline $\mathrm{S} 15.2 \mathrm{O}(\mathrm{s}) \rightarrow \mathrm{O}_{2}+2 \mathrm{Pt}(\mathrm{s})$ & $3.7 \times 10^{21}$ & 0.0 & $213.2-60 \theta_{O}$ \\
\hline S16. $2 \mathrm{H}(\mathrm{s}) \rightarrow \mathrm{H}_{2}+2 \mathrm{Pt}(\mathrm{s})$ & $3.7 \times 10^{21}$ & 0.0 & $67.4-6 \theta_{H}$ \\
\hline $\mathrm{S} 17 . \mathrm{H}_{2} \mathrm{O}(\mathrm{s}) \rightarrow \mathrm{H}_{2} \mathrm{O}+\mathrm{Pt}(\mathrm{s})$ & $1.0 \times 10^{13}$ & 0.0 & 40.3 \\
\hline $\mathrm{S} 18 . \mathrm{OH}(\mathrm{s}) \rightarrow \mathrm{OH}+\mathrm{Pt}(\mathrm{s})$ & $1.0 \times 10^{13}$ & 0.0 & 192.8 \\
\hline $\mathrm{S} 19 . \mathrm{CO}_{2}(\mathrm{~s}) \rightarrow \mathrm{CO}_{2}+\mathrm{Pt}(\mathrm{s})$ & $1.0 \times 10^{13}$ & 0.0 & 20.5 \\
\hline $\mathrm{S} 20 . \mathrm{CO}(\mathrm{s}) \rightarrow \mathrm{CO}+\mathrm{Pt}(\mathrm{s})$ & $1.0 \times 10^{13}$ & 0.0 & 125.5 \\
\hline
\end{tabular}

${ }^{(a)}$ From Deutschmann et al. (2000). In the surface and desorption reactions, the reaction rate coefficient is $k=A T^{b} \exp (-E / R T), A$ [mole-cm-Kelvin-s] and $E[\mathrm{~kJ} / \mathrm{mol}]$. In the adsorption reactions, except $\mathrm{S} 2, \mathrm{~S} 3$ and $\mathrm{S} 8$, $A$ denotes a sticking coefficient $(\gamma)$. Reactions S1 and S2 are duplicate. Reactions S3 and S13 have a Pt-order of 1 and 2, respectively. The suffix (s) denotes a surface species and $\theta_{i}$ the coverage of surface species $i$. 
Table A2 Homogeneous chemical reaction mechanism for $\mathrm{H}_{2} / \mathrm{CO}^{(a)}$

\begin{tabular}{|c|c|c|c|}
\hline & $A$ & $b$ & $E$ \\
\hline \multicolumn{4}{|l|}{$\mathrm{H}_{2} / \mathrm{O}_{2}$ reactions } \\
\hline 1. $\mathrm{H}+\mathrm{O}_{2}=\mathrm{O}+\mathrm{OH}$ & $5.20 \times 10^{15}$ & -0.46 & 70.09 \\
\hline 2. $\mathrm{O}+\mathrm{H}_{2}=\mathrm{H}+\mathrm{OH}$ & $8.97 \times 10^{3}$ & 2.90 & 26.44 \\
\hline 3. $\mathrm{H}_{2}+\mathrm{OH}=\mathrm{H}_{2} \mathrm{O}+\mathrm{H}$ & $2.17 \times 10^{8}$ & 1.52 & 14.47 \\
\hline 4. $\mathrm{OH}+\mathrm{OH}=\mathrm{O}+\mathrm{H}_{2} \mathrm{O}$ & $3.57 \times 10^{4}$ & 2.40 & -8.84 \\
\hline \multicolumn{4}{|l|}{$\mathrm{H}_{2} / \mathrm{O}_{2}$ dissociation-recombination } \\
\hline 5. $\mathrm{H}+\mathrm{H}+\mathrm{M}=\mathrm{H}_{2}+\mathrm{M}$ & $1.01 \times 10^{17}$ & -0.6 & 0.00 \\
\hline 6. $\mathrm{O}+\mathrm{O}+\mathrm{M}=\mathrm{O}_{2}+\mathrm{M}$ & $5.40 \times 10^{13}$ & 0.00 & -7.40 \\
\hline 7. $\mathrm{H}+\mathrm{OH}+\mathrm{M}=\mathrm{H}_{2} \mathrm{O}+\mathrm{M}$ & $2.19 \times 10^{22}$ & -2.00 & 0.00 \\
\hline \multicolumn{4}{|l|}{$\mathrm{HO}_{2}$ formation-consumption } \\
\hline 8. $\mathrm{H}+\mathrm{O}_{2}+\mathrm{M}=\mathrm{HO}_{2}+\mathrm{M}$ & $1.47 \times 10^{12}$ & 0.60 & 0.00 \\
\hline $\mathrm{H}+\mathrm{O}_{2}+\mathrm{M}=\mathrm{HO}_{2}+\mathrm{M}$ & $2.11 \times 10^{18}$ & -0.80 & 0.00 \\
\hline 9. $\mathrm{HO}_{2}+\mathrm{H}=\mathrm{H}_{2}+\mathrm{O}_{2}$ & $1.05 \times 10^{14}$ & 0.00 & 8.56 \\
\hline 10. $\mathrm{HO}_{2}+\mathrm{H}=\mathrm{OH}+\mathrm{OH}$ & $4.46 \times 10^{14}$ & 0.00 & 5.82 \\
\hline 11. $\mathrm{HO}_{2}+\mathrm{H}=\mathrm{H}_{2} \mathrm{O}+\mathrm{O}$ & $1.45 \times 10^{12}$ & 0.00 & 0.00 \\
\hline 12. $\mathrm{HO}_{2}+\mathrm{O}=\mathrm{OH}+\mathrm{O}_{2}$ & $1.63 \times 10^{13}$ & 0.00 & -1.86 \\
\hline 13. $\mathrm{HO}_{2}+\mathrm{OH}=\mathrm{H}_{2} \mathrm{O}+\mathrm{O}_{2}$ & $3.91 \times 10^{16}$ & 0.00 & 88.79 \\
\hline \multicolumn{4}{|l|}{$\mathrm{H}_{2} \mathrm{O}_{2}$ formation-consumption } \\
\hline 14. $2 \mathrm{HO}_{2}=\mathrm{H}_{2} \mathrm{O}_{2}+\mathrm{O}_{2}$ & $4.22 \times 10^{14}$ & 0.00 & 50.14 \\
\hline 15. $2 \mathrm{HO}_{2}=\mathrm{H}_{2} \mathrm{O}_{2}+\mathrm{O}_{2}$ & $1.32 \times 10^{11}$ & 0.00 & -6.82 \\
\hline 16. $\mathrm{OH}+\mathrm{OH}+\mathrm{M}=\mathrm{H}_{2} \mathrm{O}_{2}+\mathrm{M}$ & $1.57 \times 10^{13}$ & 0.00 & 0.00 \\
\hline $\mathrm{OH}+\mathrm{OH}+\mathrm{M}=\mathrm{H}_{2} \mathrm{O}_{2}+\mathrm{M}$ & $5.98 \times 10^{19}$ & -0.80 & 0.00 \\
\hline 17. $\mathrm{H}_{2} \mathrm{O}_{2}+\mathrm{H}=\mathrm{H}_{2}+\mathrm{HO}_{2}$ & $1.68 \times 10^{12}$ & 0.00 & 15.71 \\
\hline 18. $\mathrm{H}_{2} \mathrm{O}_{2}+\mathrm{H}=\mathrm{H}_{2} \mathrm{O}+\mathrm{OH}$ & $1.02 \times 10^{13}$ & 0.00 & 14.97 \\
\hline 19. $\mathrm{H}_{2} \mathrm{O}_{2}+\mathrm{O}=\mathrm{OH}+\mathrm{HO}_{2}$ & $4.21 \times 10^{11}$ & 0.00 & 16.63 \\
\hline 20. $\mathrm{H}_{2} \mathrm{O}_{2}+\mathrm{O}=\mathrm{H}_{2} \mathrm{O}+\mathrm{O}_{2}$ & $4.21 \times 10^{11}$ & 0.00 & 16.63 \\
\hline 21. $\mathrm{H}_{2} \mathrm{O}_{2}+\mathrm{OH}=\mathrm{H}_{2} \mathrm{O}+\mathrm{HO}_{2}$ & $1.64 \times 10^{18}$ & 0.00 & 123.05 \\
\hline 22. $\mathrm{H}_{2} \mathrm{O}_{2}+\mathrm{OH}=\mathrm{H}_{2} \mathrm{O}+\mathrm{HO}_{2}$ & $1.90 \times 10^{12}$ & 0.00 & 1.79 \\
\hline \multicolumn{4}{|l|}{$\mathrm{CO}$ reactions } \\
\hline 23. $\mathrm{CO}+\mathrm{OH}=\mathrm{CO}_{2}+\mathrm{H}$ & $4.76 \times 10^{7}$ & 1.23 & 0.29 \\
\hline 24. $\mathrm{CO}+\mathrm{HO}_{2}=\mathrm{CO}_{2}+\mathrm{OH}$ & $1.50 \times 10^{14}$ & 0.00 & 98.70 \\
\hline 25. $\mathrm{CO}+\mathrm{O}+\mathrm{M}=\mathrm{CO}_{2}+\mathrm{M}$ & $7.10 \times 10^{13}$ & 0.00 & -19.00 \\
\hline 26. $\mathrm{CO}+\mathrm{O}_{2}=\mathrm{CO}_{2}+\mathrm{O}$ & $2.50 \times 10^{12}$ & 0.00 & 200.00 \\
\hline \multicolumn{4}{|l|}{$\mathrm{HCO}$ reactions } \\
\hline 27. $\mathrm{HCO}+\mathrm{M}=\mathrm{CO}+\mathrm{H}+\mathrm{M}$ & $3.95 \times 10^{14}$ & 0.00 & 70.30 \\
\hline 28. $\mathrm{HCO}+\mathrm{H}=\mathrm{CO}+\mathrm{H}_{2}$ & $9.00 \times 10^{13}$ & 0.00 & 0.00 \\
\hline 29. $\mathrm{HCO}+\mathrm{O}=\mathrm{CO}+\mathrm{OH}$ & $3.00 \times 10^{13}$ & 0.00 & 0.00 \\
\hline 30. $\mathrm{HCO}+\mathrm{O}=\mathrm{CO}_{2}+\mathrm{H}$ & $3.00 \times 10^{13}$ & 0.00 & 0.00 \\
\hline 31. $\mathrm{HCO}+\mathrm{OH}=\mathrm{CO}+\mathrm{H}_{2} \mathrm{O}$ & $1.00 \times 10^{14}$ & 0.00 & 0.00 \\
\hline 32. $\mathrm{HCO}+\mathrm{O}_{2}=\mathrm{CO}+\mathrm{HO}_{2}$ & $3.00 \times 10^{12}$ & 0.00 & 0.00 \\
\hline 33. $\mathrm{HCO}+\mathrm{HCO}=\mathrm{CH}_{2} \mathrm{O}+\mathrm{CO}$ & $3.00 \times 10^{13}$ & 0.00 & 0.00 \\
\hline
\end{tabular}

${ }^{(a)}$ From Warnatz $(1996 ; 2005)$. Reaction rate $k=A T^{b} \exp (-E / R T), A$ [mole-cm-Kelvin-s], $E[\mathrm{~kJ} / \mathrm{mol}]$. Third body efficiencies: $\omega\left(\mathrm{H}_{2} \mathrm{O}\right)=6.5, \omega\left(\mathrm{O}_{2}\right)=\omega\left(\mathrm{N}_{2}\right)=0.4, \omega\left(\mathrm{H}_{2}\right)=1.0, \omega(\mathrm{CO})=0.75, \omega\left(\mathrm{CO}_{2}\right)=$ 1.5. The reaction pairs $(14,15)$ and $(21,22)$ are duplicate. Reactions 8 and 16 are Troe reactions centered at 0.5 (second entries are the low pressure limits). 